\title{
Modulation of the Gut Microbiota by Olive Oil Phenolic Compounds: Implications for Lipid Metabolism, Immune System, and Obesity
}

\author{
Marta Farràs ${ }^{1,2, *}$, Laura Martinez-Gili ${ }^{3} \mathbb{D}$, Kevin Portune ${ }^{4}$, Sara Arranz ${ }^{4}\left(\mathbb{D}\right.$, Gary Frost ${ }^{5}$, \\ Mireia Tondo ${ }^{6,+}$ D and Francisco Blanco-Vaca $2,6,7,+$ \\ 1 Institut de Recerca de l'Hospital Santa Creu i Sant Pau, Institut d'Investigacions Biomèdiques (IIB) Sant Pau, \\ 08041 Barcelona, Spain \\ 2 CIBER de Diabetes y Enfermedades Metabólicas Asociadas (CIBERDEM), 08907 Barcelona, Spain; \\ fblancova@santpau.cat \\ 3 Division of Systems Medicine, Department of Metabolism, Digestion and Reproduction, Faculty of Medicine, \\ Imperial College London, London SW7 2AZ, UK; laura.martinez@imperial.ac.uk \\ 4 AZTI, Food Research, Basque Research and Technology Alliance (BRTA), Parque Tecnológico de Bizkaia, \\ AstondoBidea, Edificio 609, 48160 Derio, Spain; kportune@azti.es (K.P.); sarranz@azti.es (S.A.) \\ 5 Division of Digestive Diseases, Department of Metabolism, Digestion and Reproduction, \\ Faculty of Medicine, Imperial College London, London SW7 2AZ, UK; g.frost@imperial.ac.uk \\ 6 Hospital de la Santa Creu i Sant Pau, Servei de Bioquímica-Institut d'Investigacions Biomèdiques (IIB) Sant \\ Pau, 08041 Barcelona, Spain; mtondo@santpau.cat \\ 7 Departament de Bioquímica i Biologia Molecular, Universitat Autònoma de Barcelona, \\ 08193 Barcelona, Spain \\ * Correspondence: mfarras@santpau.cat; Tel.: +34-935537595 \\ + This two authors contributed equally to this paper.
}

Received: 20 June 2020; Accepted: 20 July 2020; Published: 23 July 2020

\begin{abstract}
There is extensive information of the beneficial effects of virgin olive oil (VOO), especially on cardiovascular diseases. Some VOO healthy properties have been attributed to their phenolic-compounds (PCs). The aim of this review is to present updated data on the effects of olive oil (OO) PCs on the gut microbiota, lipid metabolism, immune system, and obesity, as well as on the crosstalk among them. We summarize experiments and clinical trials which assessed the specific effects of the olive oil phenolic-compounds (OOPCs) without the synergy with OO-fats. Several studies have demonstrated that OOPC consumption increases Bacteroidetes and/or reduces the Firmicutes/Bacteroidetes ratio, which have both been related to atheroprotection. OOPCs also increase certain beneficial bacteria and gut-bacteria diversity which can be therapeutic for lipid-immune disorders and obesity. Furthermore, some of the mechanisms implicated in the crosstalk between OOPCs and these disorders include antimicrobial-activity, cholesterol microbial metabolism, and metabolites produced by bacteria. Specifically, OOPCs modulate short-chain fatty-acids produced by gut-microbiota, which can affect cholesterol metabolism and the immune system, and may play a role in weight gain through promoting satiety. Since data in humans are scarce, there is a necessity for more clinical trials designed to assess the specific role of the OOPCs in this crosstalk.
\end{abstract}

Keywords: gut microbiota; immune system; lipids; obesity; olive oil; phenolic compounds

\section{Introduction}

The Mediterranean diet has been demonstrated to reduce the risk of cardiovascular diseases (CVD), cancer, neurodegenerative diseases, and diabetes [1]. Concretely, the PREDIMED study, the largest Mediterranean-diet trial, has extensively studied the effects of this diet on such diseases and the 
outcomes reviewed in the present work in cardiovascular risk individuals (Supplementary Table S1). The main source of fat in the Mediterranean diet is virgin olive oil (VOO) which also presents numerous beneficial effects, especially on cardiovascular diseases [2,3]. Improvement of blood pressure and protection of the intestinal mucosa have been attributed to olive oil (OO) fatty acids, especially to oleic acid, the most abundant lipid in OO [4,5]. Nevertheless, other healthy properties have also been attributed to the phenolic compounds (PCs) present in VOO. In that sense, several studies have reported beneficial effects of the olive oil phenolic-compounds (OOPCs). The Eurolive clinical trial with 200 healthy participants demonstrated that OOPCs increased high-density lipoprotein cholesterol (HDL-c) and decreased lipid oxidative damage in a dose-dependent way [6]. In this regard, in 2011, the European Food Safety Authority, recommended the consumption of OO with at least $5 \mathrm{mg}$ of hydroxytyrosol (HT) (the main OOPC) and its derivatives per $20 \mathrm{~g}$ of OO to protect from lipid oxidative damage. Further, OOPCs enhance the expression of cholesterol-efflux related genes in circulating white blood cells of pre-/hypertensive patients [7] and improve endothelial function and HDL characteristics in hypercholesterolemic patients [8,9]. Altogether, these lipid profile improvements after VOO consumption could contribute to the cardioprotective properties observed in the Mediterranean diet.

Since it is well known that changes in the gut microbiome influence CVD [10], studying the effects of OOPCs on the gut microbiome may shed some light on additional involved mechanisms. To date, few studies have addressed this issue. It has been described that diet influences the intestinal microbiota, producing various enterotypes [11] with a predictable composition [12] according to the type of food ingested. Specifically, dietary fat intake has been described as one of the factors influencing gut microbiota composition [13], such as the Firmicutes/Bacteroidetes ratio, which is decreased in overweight and obese subjects compared to normal weight controls [14-17]. Protein, carbohydrates, and indigestible fiber are also relevant substrates and modulators of gut microbiota, as well as dietary PCs, which can be catabolized and transformed by gut microorganisms changing their biological activity and availability for the host. PCs enhance the growth of bacteria associated with healthy metabolic markers such as Bifidobacteria, Lactobacillus, Akkermansia spp., and Faecalibacterium spp. This prebiotic effect has been observed with higher intake of foods rich in PCs such as cocoa, pomegranate, nuts, grape, wine, tea, and berries [18].

Microorganism abundance and diversity across the human gastrointestinal tract increase longitudinally from the stomach to the colon $[19,20]$, with more than 1000 different species of bacteria in the human intestinal tract and around 38 trillion bacteria resident in the colon [21]. Gut microbes have relevant roles in host metabolic and immune homeostasis, and a disturbed microbiota, altered intestinal permeability, and inflammation have been observed in obesity [22], insulin resistance [23], and CVD. Furthermore, obesity and CVD share some of the microbiota alterations found in these studies [24].

Gut microbial-derived metabolites may also play a key role in immune homeostasis and host susceptibility to immune-mediated pathologies and alterations [25].For example, short chain fatty acids (SCFA) produced from the diet are important modulators of the immune system and may play a role in weight loss in obesity through promoting satiety [26]. Another example is the microbial-host cometabolite trymethylamine-N-oxide (TMAO) which affects lipid metabolism and atherosclerosis [27].

Overall, OOPCs from the diet can influence the gut microbiota and its metabolism, thereby affecting human health and disease. The aim of this review is to present up-to-date information on the OOPC's effects on gut microbiome, lipid metabolism, immune system, and obesity, as well as the crosstalk among them.

\section{Olive Oil Composition}

The Mediterranean diet is particularly rich in OO, fruits, vegetables, legumes, nuts, and seafood. In contrast, Western diets are characterized as being rich in processed meats, sugar-sweetened soft drinks, and refined grains [28]. OO is the main fat source in the Mediterranean diet which, as previously 
stated, is characterized for improving cardiovascular risk and cardiovascular and total mortality risk [2,3]. The major compounds of OO are fatty acids (98\%), specifically, monounsaturated fatty acids (55-83\%; oleic acid and palmitoleic acid), polyunsaturated fatty acids (11-42.5\%; linolenic acid, linoleic acid), and saturated fatty acids (8-25.1\%; palmitic acid, myristic acid, stearic acid). The minor compounds include lipophilic PCs (tocopherols and tocotrienols), hydrophilic PCs (phenolic acids, phenolic alcohols, secoirioids, lignans, and flavones), volatile compounds, pigments (chlorophylls), hydrocarbons (squalene, $\beta$-carotene, lycopene), sterols ( $\beta$-sitosterol, campesterol, estigmasterol), triterpene and aliphatic alcohols, and nonglyceride esters (alcoholic and sterol compounds, waxes). These minor compounds help to preserve vitamin $\mathrm{E}$ and increase $\mathrm{OO}$ nutritional and sensorial properties. The principal minor compound of OO is HT, a PC with health properties. Another OO compound with extensively demonstrated health properties is oleuropein, which is found mainly in olive leaves but also in small quantities in OO itself [29].

$\mathrm{VOO}$ and extra VOO are obtained by direct pressing or centrifugation of the olives and it is rich in PCs (ranging from $\sim 150$ to 400 ppm in currently marketed commercial OOs). VOO also has a very good sensorial quality due to its low acidity index $(<0.8 \%)$. A major beneficial effect of VOO is the reduction of LDL susceptibility to oxidation [30]. Refined OO, on the other hand, is obtained by mechanical extraction from unsuitable fruits and the majority of OOPCs in this type of OO are lost during refinement procedures [31]. In general, VOOs currently in the market do not achieve the quantity of PCs recommended by European Food Safety Authority. Therefore, functional enriched OOs are being manufactured to increase PC concentrations in VOOs without increasing its fat content. Moreover, functional OOs enriched with complementary PCs have more beneficial effects than OOs enriched with only OOPCs [32].

\section{Olive Oil Phenolic Compounds and Gut Microbiota}

\subsection{Metabolism of OOPCs by Gut Microbiota}

Effects of single OOPCs on gut microbiota have been described in the literature. The studies of this section are shown in Table 1.

Complex phenols undergo hydrolysis in the stomach due to its acidic environment, thereby increasing the proportion of simple phenols, such as tyrosol and HT, that will reach the duodenum [33]. While most of the simple phenols are rapidly absorbed in the small intestine, some simple and complex phenols reach the large intestine, where they can be metabolized by resident microbiota. Studies performed with batch fermentation of human colonic microbiota observed that oleuropein could be catabolized into HT [33], which in turn could be further oxidized into 2-( $3^{\prime}, 4^{\prime}$-dihydroxyphenyl)acetic acid, followed by a dehydroxylation to 2-(4'-hydroxyphenyl)acetic acid and phenylacetic acid. Tyrosol could be oxidized into 2-(4'-hydroxyphenyl) acetic acid [34]. This latter study also detected HT acetate as another microbial metabolite product of oleuropein metabolism, which could either be hydrolyzed back into HT or converted to 3-(4'-hydroxyphenyl) propionic acid.

Isolated strains have been cultured to identify microbes responsible for such reactions. When grown in vitro, bacteria from the genera Lactobacillus, Bifidobacteria, and Enterococcus hydrolyse oleuropein to form HT [35]. Among the Lactobacillus genus, Lactobacillus plantarum is able to catabolize oleuropein into HT, as well as carry out the decarboxylation of protocatechuic acid into catechol [36] and hydroxycinnamic acids, like p-coumaric acid, into 4-ethylphenol and 4-ethylguaiacol $[37,38]$.

The metabolism of less abundant OOPCs has also been assessed. Microbe suspensions from human faecal slurries are able to degrade apigenin, an OOPC, into different products such as 3-(4'-hydroxyphenyl) propionic acid [39]. The same study also showed excretion of apigenin microbial products in urine and faeces of germ-free rats humanized with human microbiota. The presence of PCs in serum, faeces, and urine has been measured after oral administration of apigenin, luteolin and other flavonoids by gavage into mice treated or not with antibiotics. After oral administration, serum flavonoid concentrations were not different between the two groups, indicating no differences 
in intestinal absorption. However, mice preserving their native microbiota excreted higher levels of phenolics in faeces and urine [40]. Clostridium orbiscindens [41] and a strain from the Lachnospiraceae family isolated from human faeces [42] are among identified microbes that are able to metabolize apigenin and luteolin.

Caffeic acid is another OOPC which is found in many other plants, mostly esterified with quinic acid in the form of chlorogenic acid. In human microbiota colonic cultures, caffeic acid can be catabolized to 3-hydroxyphenylpropionic and benzoic acids [43,44]. Ferulic acid can also be catabolized to 3-hydroxyphenylpropionic acid in colonic batch fermentations, sharing some of the catabolic pathways and products previously described [45].

Acteoside is a complex phenol made of a disaccharide, HT, and caffeic acid, which can be catabolized into its constituents HT and caffeic acid by human colonic cultures [46]. However, it is not yet known which microbial species are able to use acteoside as a substrate.

Pinoresinol, a lignan present in OO, is reduced to lariciresinol by Enterococcus faecalis [47] and Eggerthellalenta [48], two species commonly present in the gut microbiota.

Syringic acid can be demethylated to gallic acid by Peptostreptococcusproductus, Eubacteriumlimosum, Eubacteriumcallanderi, and Butyribacterium methylotrophicum [48].

The gut microbiome also has the potential to decarboxylate gallic acid into pyrogallol. Gallic acid decarboxylase gene was found in species belonging to the phyla Firmicutes, Proteobacteria, and Actinobacteria [49].

Little is known about the impact of OOPCs on microbiota located in the small intestine. In this regard, a couple of studies using microbes isolated from pig caeca observed that they were able to metabolize apigenin glycosides [50] and catabolize luteolin into 3-(3-hydroxyphenyl)-propionic acid [51]. To our knowledge, no studies have assessed OOPC microbial metabolism in the jejunum or ileum so far.

\subsection{Antimicrobial Properties of OOPC}

The studies of this section are shown in Table 1.

$\mathrm{OO}$ and its phenol extracts have long been known to have in vitro antimicrobial properties against common pathogens like Staphylococcus aureus and Escherichia coli [52,53] and also against in vitro cultured commensal bacteria, such as Lactobacillus acidophilus and Bifidobacterium bifidum [54].

Pure OOPCs have also been tested against isolated gut microbial strains or faecal slurries in vitro [55]. Caffeic acid inhibited the growth of both common pathogenic and commensal strains. In contrast, gallic acid did not have antimicrobial properties but rather could actually promote the growth of some pathogens like Escherichia coli O157:H7 [56]. Interestingly, microbial products from the metabolism of these two phenols also inhibited the growth of many microbial species.

Antimicrobial activity of many OOPCs was confirmed by Karaosmanoglu et al. using cultured bacterial strains. Cinnamic, ferulic, 4-hydroxybenzoic, vanillic and syringic acids as well as luteolin, vanillin and tyrosol exhibited antimicrobial properties against Escherichia coli O157:H7, Listeria monocytogenes and Salmonella enteritidis [57].

Apigenin was able to reduce the growth of Bacteroides galacturonicus and Enterococcus caccaein isolated cultures but promoted Enterococcus growth, SCFA production, and microbial diversity when added to human faecal colonic batch cultures [58]. This discrepancy between isolated cultures and colonic batch fermentation shows the complexity of microbial community dynamics. In addition, another study using a similar experimental setting with faecal cultures from three different donors and $200 \mu \mathrm{M}$ of apigenin (instead of $370 \mu \mathrm{M}$ used in the previously mentioned study), did not detect changes in microbial composition or SCFA production [59]. The different doses of apigenin, the use of frozen versus fresh faeces in the batch cultures, respectively, and the interindividual differences of microbial composition between donors could be the main reasons for these discrepant findings. Interestingly, an indirect effect of apigenin on gut microbiota composition, relying on host NOD-like receptor pyrin 
domain-containing protein 6 (NLRP6) signaling, was observed in mice [60]. This shows the potential of OOPCs to act as bioactive molecules further modulating host pathways and microbial composition.

While many of these studies were in vitro, it is important to note that in vitro experimental settings may not realistically reflect the intestinal lumen environment, the different compounds' bioavailability, and the microbial community dynamics.

\subsection{Microbiota Composition Modulation by OOPC}

Human nutritional studies assessing the relationship between OOPCs and gut microbiota are scarce and often use whole OO dietary supplementation with a poor control of the overall diet composition between participants. This creates two strong confounding sources. First, the gut microbiota composition can be influenced by both the lipidic content in OO [61] and second by the differing consumption of phenol-containing foods between participants which can change phenolic bioavailability. Therefore, it is difficult to draw clear conclusions on the specific impact of OOPC on the microbiome in humans without considering such confounders. The VOO and HDL functionality (VOHF) study was a randomized, controlled, double-blind, crossover clinical trial [32] in which hypercholesterolemic participants ingested one of three VOOs $(25 \mathrm{~mL} /$ day) for three weeks: raw, supplemented with OOPCs or supplemented with PCs from both OO and thyme. Importantly, lipidic composition was the same among the oils tested and dietary intake was monitored. In a subsample of participants, a subset of preselected bacterial groups was quantified using fluorescence in situ hybridization (FISH) and fluorescence-activated cell sorting (FACS) techniques showing modest changes in microbial composition of Bifidobacterium spp. and Parascardovia denticolens. Nevertheless, microbial changes could be underestimated due to the low number of participants and the limited coverage and resolutive power of the probes used to quantify microbial composition [62].

In a preclinical study, mice were fed a chow or high-fat diet enriched in extra VOO, refined OO, or butter for three months [63]. Mice fed an extra VOO diet had an increase in abundance of bacteria from the families Sutterellaceae and Erysipelotrichaceae and a decrease in Christensenellaceae and Prevotellaceae when compared to chow diets. At the genus level, mice fed extra VOO had a decreased abundance in Desulfovibrio with respect to refined $\mathrm{OO}$ and a decrease in Anaerophaga and Fusicatenibacter and an increase in Parasutterella and Marinilabilia compared to the chow diet. However, as mentioned previously, changes in microbial composition between chow and extra VOO diets could also be attributed to differences in their lipidic content.

The Firmicutes/Bacteroidetes ratio is a biomarker of altered colonic microbial composition [15-17]. A diet high in lipids can increase this ratio, and dietary supplementation with OOPCs such as HT in mice fed with high fat diet does not restore this ratio but increases the abundance of the genus Lactobacillus $[16,64,65]$. Murine in vivo studies also assessed the effect of single OOPCs on gut microbiota and the Firmicutes/Bacteroidetes ratio. Supplementing caffeic acid in drinking water ameliorated symptoms of dextran sulfate sodium (DSS)-induced colitis, reduced the Firmicutes/Bacteroidetes ratio and increased abundance of Verrucomicrobia phyla [66] (Table 1). Microbial changes of caffeic acid supplementation in control mice were not determined. In apolipoprotein $\mathrm{E}$ knockout mice $\left(\mathrm{APOE}^{-/-}\right)$fed a high-fat diet, oral ferulic acid administration reduced the Firmicutes/Bacteroidetes ratio. However, the effect of oral ferulic acid on $\mathrm{APOE}^{-/-}$mice fed a control diet was not assessed [67] (Table 1). Mice exposed to airborne particulate matter and gavaged with HT, exhibited an increase in Ruminococcaceae and Mycoplasmataceae bacterial families. Again, the effect of HT on microbiota composition in control mice was not assessed or shown [68] (Table 1).

Similar results were reported in studies in which gut microbiota diversity was analyzed. Higher biodiversity of the gut microbiota was observed in hypertensive rats after administration of VOO, although the complete microbial populations in these groups were not fully characterized due to the limited molecular techniques applied [64]. 
Table 1. Studies which analyzed the effects of singleolive oil phenolic-compounds (OOPC) on gut microbiota and pathogens.

\begin{tabular}{|c|c|c|c|}
\hline Compound & Experiment Setting & Effect & Reference \\
\hline \multirow{6}{*}{ Apigenin } & Caecum microbiota from pig (in vitro) & $\begin{array}{l}\text { Degradation of apigenin monoglycoside into 3,4-dihydroxyphenylacetic acid or } \\
\text { 4-hydroxyphenylacetic acid }\end{array}$ & [50] \\
\hline & $\begin{array}{l}\text { (1) Human faecal slurries (in vitro) or (2) Drinking } \\
\text { water supplement in germ-free rats inoculated with } \\
\text { human microbiota (in vivo) }\end{array}$ & $\begin{array}{l}\text { (1) Conversion of apigenin into 3-(3,4-dihydroxyphenyl)propionic acid and } \\
\text { 3-(3-hydroxyphenyl)propionic acid (2) Excretion of naringenin, phloretin, } \\
\text { eriodictyol, 3-(3,4-dihydroxyphenyl)propionic acid, } \\
\text { 3-(4-hydroxyphenyl)propionic acid, 4-hydroxycinnamic acid, and } \\
\text { 3-(3-hydroxyphenyl)propionic acid in urine and faeces. }\end{array}$ & [39] \\
\hline & Lachnospiraceae isolated strain from human faeces & Conversion of apigenin to 3-(4-hydroxyphenyl)propionic acid & [42] \\
\hline & Bacteria strains or colonic communities (in vitro) & $\begin{array}{l}\text { Different effects in bacterial growth and production of short chain fatty } \\
\text { acids (SCFA) }\end{array}$ & [58] \\
\hline & $\begin{array}{l}\text { Clostridium orbiscindens isolated strain from } \\
\text { human faeces }\end{array}$ & Conversion of apigenin to 3-(4-hydroxyphenyl)propionic acid & [41] \\
\hline & $\begin{array}{l}\text { (1) Mouse faecal suspensions (in vitro) and (2) mice } \\
\text { gavaged with polyphenols with or without } \\
\text { antibiotic treatment (in vivo) }\end{array}$ & $\begin{array}{l}\text { (1) p-Hydroxybenzoic acid, p-Hydroxyphenylacetic acid, caffeic acid, } \\
\text { 3-(4-Hydroxyphenyl)propionic acid and p-Coumaric acid were detected in the } \\
\text { incubated faecal suspensions. (2) Serum protocatechuic and } \\
\text { p-hydroxyphenylacetic acids were higher in the nontreated animals. Faecal and } \\
\text { urine excretion were comparable and higher for nontreated mice. Vanillic acid } \\
\text { was found in urine. }\end{array}$ & [40] \\
\hline Benzoic/4-hydroxybenzoic acid & Bacterial strains in culture (in vitro) & $\begin{array}{l}\text { Antimicrobial properties against Escherichia coli O157:H7, Listeria monocytogenes } \\
\text { and Salmonella enteritidis }\end{array}$ & [57] \\
\hline \multirow{3}{*}{ Caffeic acid } & Human faecal slurries (in vitro) & $\begin{array}{l}\text { Caffeic acid (free or esterified with quinic or tartaric acids) was converted to } \\
\text { 3-hydroxyphenyl propionic acid and benzoic acid }\end{array}$ & [44] \\
\hline & Bacterial strains in culture (in vitro) & $\begin{array}{l}\text { Each strain was affected differently. Marked growth inhibition of pathogens, but } \\
\text { different effects on other species. }\end{array}$ & [56] \\
\hline & $\begin{array}{l}\text { Mice with DSS-induced colitis supplemented } \\
\text { caffeine in drinking water }\end{array}$ & $\begin{array}{l}\text { Reduced the Firmicutes/Bacteroidetes ratio and increased abundance of } \\
\text { Verrucomicrobia phyla }\end{array}$ & [66] \\
\hline Cinnamic acid & Bacterial strains in culture (in vitro) & $\begin{array}{l}\text { Antimicrobial properties against Escherichia coli O157:H7, Listeria monocytogenes } \\
\text { and Salmonella enteritidis }\end{array}$ & [57] \\
\hline Coumaric acid & Lactobacillus plantarum cultured strains (in vitro) & Decarboxylation of p-coumaric acid into 4-ethylphenol and 4-ethylguaiacol & [37] \\
\hline Demethyloleuropein & no results in Pubmed & not investigated in the context of microbiome & - \\
\hline
\end{tabular}


Table 1. Cont.

\begin{tabular}{|c|c|c|c|}
\hline Compound & Experiment Setting & Effect & Reference \\
\hline \multirow{3}{*}{ Ferulic } & $\mathrm{APOE}^{-/-}$mice gavaged with ferulic acid (in vivo) & Reduction of the Firmicutes/Bacteroidetes ratio & [67] \\
\hline & Human faecal slurries (in vitro) & $\begin{array}{l}\text { Conversion of ferulic acid into (hydroxy)phenylacetic and (hydroxy)benzoic } \\
\text { acid derivatives }\end{array}$ & [45] \\
\hline & Bacterial strains in culture (in vitro) & $\begin{array}{l}\text { Antimicrobial properties against Escherichia coli O157:H7, Listeria monocytogenes } \\
\text { and Salmonella enteritidis }\end{array}$ & [57] \\
\hline \multirow[b]{2}{*}{ Gallic acid } & Bacteria strains or colonic communities (in vitro) & $\begin{array}{l}\text { Conversion of gallic acid to pyrogallol by species pertaining to the phyla } \\
\text { Firmicutes, Proteobacteria and Actinobacteria. }\end{array}$ & [49] \\
\hline & Bacterial strains in culture (in vitro) & $\begin{array}{l}\text { Each strain was affected differently. Marked growth inhibition of some } \\
\text { pathogens like Clostridioides difficile, but promoted growth of others like } \\
\text { Escherichia coli 0157:H7 or Salmonella enterica Typhimurium. }\end{array}$ & [56] \\
\hline \multirow{2}{*}{ Hydroxytyrosol } & $\begin{array}{l}\text { Mice gavaged with hydroxytyrosol and exposed to } \\
\text { particulate matter (in vivo) }\end{array}$ & Increase in Ruminococcaceae and Mycoplasmataceae families abundance & [68] \\
\hline & Human faecal slurries (in vitro) & Hydroxytyrosol is oxidised into 2-( $3^{\prime}, 4^{\prime}$-dihydroxyphenyl)acetic acid & [34] \\
\hline Ligstroside & no results in Pubmed & not investigated in the context of microbiome & - \\
\hline \multirow{4}{*}{ Luteolin } & $\begin{array}{c}\text { (1) Mouse faecal suspensions and (2) mice gavaged } \\
\text { with polyphenols with or without } \\
\text { antibiotic treatment }\end{array}$ & $\begin{array}{l}\text { (1) p-Hydroxybenzoic acid, Protocatechuic acid, p-Hydroxyphenylacetic acid } \\
\text { and 3-(4-Hydroxyphenyl)propionic acid were detected in the incubated faecal } \\
\text { suspensions. (2) Serum protocatechuic and hydrocaffeic acids were higher in the } \\
\text { nontreated animals. Faecal and urine excretion were comparable and higher for } \\
\text { nontreated mice. }\end{array}$ & [40] \\
\hline & Bacterial strains in culture (in vitro) & $\begin{array}{l}\text { Antimicrobial properties against Escherichia coli O157:H7, Listeria monocytogenes } \\
\text { and Salmonella enteritidis }\end{array}$ & [57] \\
\hline & Pig caecum microbiota (in vitro) & Luteolin converstion into 3-(3-hydroxyphenyl)propionic acid & [51] \\
\hline & Lachnospiraceae isolated strain from human faeces & Luteolin converstion into 3-(3,4-dihydroxyphenyl)propionic acid & [42] \\
\hline Mixture: acteoside & Human faecal slurries (in vitro) & Metabolised into hydroxytyrosol and caffeic acid & [46] \\
\hline \multirow{2}{*}{ Mixture: olive oil supplement } & $\begin{array}{l}\text { Olive oil dietary supplementation in humans } \\
\text { (in vivo) }\end{array}$ & $\begin{array}{l}\text { Changes in microbial composition of Bifidobacterium spp. and } \\
\text { Parascardoviadenticolens }\end{array}$ & [62] \\
\hline & Bacterial cultures treated with olive oils (in vitro) & $\begin{array}{l}\text { Inhibition of growth of pathogens like Escherichia coli or Clostridium perfringens } \\
\text { as well as commensals like Lactobacillus acidophilus and Bifidobacterium bifidum }\end{array}$ & [54] \\
\hline Nuezhenide & no results in Pubmed & not investigated in the context of microbiome & - \\
\hline \multirow[b]{2}{*}{ Oleuropein } & Human faecal slurries (in vitro) & Conversion of oleuropein into hydroxytyrosol & [33] \\
\hline & Bacterial strains in culture (in vitro) & $\begin{array}{l}\text { Lactobacillus, Bifidobacteria and Enterococcus genera hydrolyse oleuropein } \\
\text { into hydroxytyrosol }\end{array}$ & [35] \\
\hline
\end{tabular}


Table 1. Cont.

\begin{tabular}{|c|c|c|c|}
\hline Compound & Experiment Setting & Effect & Reference \\
\hline \multirow[b]{2}{*}{ Pinoresinol } & Eggerthellalenta isolated culture (in vitro) & Conversion of pinoresinol to lariciresinol and secoisolariciresinol & [48] \\
\hline & $\begin{array}{l}\text { Human faecal slurries and Enterococcus faecalis strain } \\
\text { (in vitro) }\end{array}$ & Conversion of pinoresinol to lariciresinol and secoisolariciresinol & [47] \\
\hline Protocatechuic acid & Lactobacillus plantarum cultured strains (in vitro) & Decarboxylation of protocatechuic acid into catechol & [36] \\
\hline \multirow{2}{*}{ Syringic acid } & Bacterial strains in culture (in vitro) & $\begin{array}{l}\text { Antimicrobial properties against Escherichia coli O157:H7, Listeria monocytogenes } \\
\text { and Salmonella enteritidis }\end{array}$ & [57] \\
\hline & Bacterial strains in culture (in vitro) & $\begin{array}{l}\text { Syringic acid can be demethylated to gallic acid by Peptostreptococcusproductus, } \\
\text { Eubacteriumlimosum, Eubacteriumcallanderi and Butyribacteriummethylotrophicum }\end{array}$ & [48] \\
\hline \multirow[b]{2}{*}{ Tyrosol } & Human faecal slurries (in vitro) & Tyrosol is oxidised into 2-(4'-hydroxyphenyl)acetic acid & [34] \\
\hline & Bacterial strains in culture (in vitro) & $\begin{array}{l}\text { Antimicrobial properties against Escherichia coli O157:H7, Listeria monocytogenes } \\
\text { and Salmonella enteritidis }\end{array}$ & [57] \\
\hline (homo)Vanillic acid & Bacterial strains in culture (in vitro) & $\begin{array}{l}\text { Antimicrobial properties against Escherichia coli O157:H7, Listeria monocytogenes } \\
\text { and Salmonella enteritidis }\end{array}$ & [57] \\
\hline
\end{tabular}


Overall, the summarized studies show the potential of OOPCs to modulate microbial composition and the capacity of gut microbes to metabolize OOPCs. However, the value of OOPCs and their microbial derivatives as potential therapeutic agents for metabolic diseases needs to be further investigated in larger randomized trials devoid of confounding sources such as OO lipids and PCs derived from other foods.

\section{Effects of Olive Oil Phenolic Compounds on Lipid Metabolism and Gut Microbiota}

Over the last two decades, an association between metabolic disorders and dyslipidemia with gut microbiota has been observed [69]. Many studies have demonstrated a positive association between low-density lipoprotein cholesterol (LDL-c) and CVD riskand a negative association with high-density lipoprotein cholesterol (HDL-c) [70,71]. In a cohort of 155 European women, it was shown that 66 metagenomic gene clusters from gut microbiota were associated with serum triglyceride (TG) concentration, two with HDL-c concentration, and none with LDL or total cholesterol concentration [72]. One Clostridiales metagenomic gene cluster was negatively correlated with TG but positively correlated with HDL-c. A study with a large cohort of 893 healthy subjects described that gut microbiota explained $6.0 \%$ of the variation for TG, $4.0 \%$ for HDL-c, and $4.5 \%$ for body mass index (BMI), independently of age, sex, and genetics [73]. Individuals with high circulating TG and low HDL-c have lower microbial diversity and functional richness, high abundance of Actinobacteria phylum, and lower abundance of Proteobacteria and Bacteroidetes phyla. In addition, a study in obese adolescents reported that the genus Ruminococcus was associated with total cholesterol, while Parvimonas was negatively associated with LDL-c, and HDL-c was positively associated with Mogibacteriaceae [74].

Several studies have reported effects of OOPCs on cholesterol metabolism; nevertheless, works assessing OOPCs, microbiota, and lipids altogether are scarce. In a subsample from the VOHF study, no changes in faecal cholesterol concentrations were observed after different $\mathrm{VOO}$ interventions. Nevertheless, an increase in coprostanone was shown after the OOPC-enriched VOO intervention [4]. Coprostanone is one of the products generated when gut microbiota metabolize cholesterol. Although PC supplementation affects gut microbiota composition and reduces cholesterol in the blood [75], no changes in blood cholesterol were observed in the study by Peláez et al. [62]. Since cholesterol is the precursor of bile acids, it would be interesting to assess whether bile acid profiles changed across the different dietary interventions.

A number of studies have indicated that oxidized LDL is associated with the severity of acute coronary events [76] and can be considered a coronary heart disease biomarker [77]. Investigations have described that LDL-c concentration and oxidized LDL decreased linearly with the PC content of various OOs [6]. By contrast, in postprandial studies in healthy volunteers, oxidized LDL increased after OO intake with high concentrations of OOPCs [8] or after high doses of VOO [78]. In a subsample of the VOHF study, the intake of a functional OO enriched with OOPC and thyme PC decreased oxidized LDL and increased Bifidobacteria and Parascardorvia genera [62]. It has been previously described that Bifidobacteria abundance increases after consumption of other PC-containing foods (wine, wild blueberry, pomegranate peel, and cocoa) [79-82]. Furthermore, it has been observed that the serum lipid profile improved after Bifidobacteria and Lactobacilli mixed probiotic supplements were administered in clinical and preclinical studies [83,84]. The increase in Bifidobacterium could be responsible for the decrease in oxidized LDL. Bifidobacterium is a beneficial bacteria, a marker of gut microbiota balance, that helps maintain the intestinal barrier and uses oleuropein as a carbon source $[17,23]$. Parascardovia was also increased after the consumption of $\mathrm{OO}$, indicating that these bacteria could also be related with the diminishing of oxidized LDL [62].

Other beneficial gut bacteria are lactobacillus. Species from Lactobacillus genus seem to be differentially affected by VOO. In hypertensive rats, the consumption of extra VOO consumption increased Lactobacillus. In this line, a study in high-fat diet-induced obese mice showed that the intake of HT (50 mg/kg) increased Lactobacillus, especially L. johnsonii [65]. In addition, it has beendescribed that probiotic bacteria can decrease total cholesterol and LDL-cholesterol $[85,86]$. In contrast, extra VOO 
consumption reduced some Lactobacillus species abundance, especially L. animalis, L. taiwanensis, and the genus Lactococcus, which correlated positively with weight [87]. In addition, olive-pomace-enriched biscuits decreased oxidized LDL and decreased the relative abundance of Lactobacillus [88]. Overall, contradictory results regarding the relationship with oxidized LDL and probiotic bacteria exist. Gut microbiota also influence the synthesis of cholesterol through regulating intestinal bile acid metabolism. Bifidobacteria among other microbes deconjugates bile acid salts [89], which are not absorbed and therefore excreted to faeces or further modified by bacteria. In order to compensate for the reduced bile acid availability, new bile acid synthesis occurs and consequently blood cholesterol levels decrease. In addition, it has been recently described that Lactobacillus could decrease blood cholesterol by diminishing fat absorption from intestine via the farnesoid $\mathrm{X}$ nuclear receptor [90]. However, no differences in either faecal bile acids or blood cholesterol were observed after OOPC intake in humans [62].

Prieto et al. [87] showed lower Desulfovibrio in the faeces of mice consuming extra VOO compared to an enriched butter diet. Nevertheless, in this study lower Desulfovibrio was not associated with lower total cholesterol levels. Total cholesterol levels correlated positively with Anaerophaga, Parasutterella, Erysipelotrichaceae, and Olivibacter and negatively with Prevotella and Fusicatenibacter. The HDL/LDL ratio negatively correlated with Parasutterella and Fusicatenibacter. In addition, increased levels of Sutterellaceae, Marispirillum, and Mucilaginibacterdageonensis were observed in mice consuming the extra VOO.

Bacteroidetes phylum is associated with atheroprotection and with reduction of intestinal permeability and plasmatic lipopolysaccharides (LPS). As previously stated, a number of in vivo studies demonstrated that extra VOO intake $[87,91]$ and some OOPCs increased Bacteroides or decreased Firmicutes/Bacteroides ratio [66,67]. However, the ratio Firmicutes/Bacteroidetes did not change after HT consumption $[16,64,65]$.

Metabolites produced by the gut microbiota can also exert effects on lipid metabolism. Trimethylamineoxide (TMAO) is a microbial-host cometabolite generated from dietary choline and L-carnitine, which are transformed to trimethylamine (TMA) by gut microbes, and then metabolized to TMAO by flavin monooxygenases in the liver. TMAO promotes atherosclerosis in animal models and is associated with CVD and adverse cardiac events in humans [92-94]. It has been described that TMAO inhibits the reverse cholesterol transport pathway. Inhibition of TMAO production is being explored as a potential therapeutic approach for atherosclerosis [95]. Nevertheless, no effects of OOPCs on TMAO are described in the literature. In contrast, OOPCs are able to affect other gut microbiota metabolites implicated on lipid metabolism, such as bioactive PC metabolites and SCFAs.

One of the bioactive PC gut microbiota metabolites that can affect lipid metabolism is protocatechuic acid. This metabolite enhances reverse cholesterol transport in mice [96] and inhibits LDL oxidation [62,97]. Protocatechuic acid was found elevated after the consumption of VOO enriched with OOPCs and thyme PCs, concomitant with a reduction of oxidized LDL [62]. The antioxidant activity of HT and other microbiota-derived compounds helps to avoid lipoprotein modifications that lead to atherosclerosis plaque formation [98].

A number of studies have shown that PC consumption induces changes in SCFA levels produced by gut microbiota [99], mainly acetate, propionate, and butyrate. Grapefruit PCs have been demonstrated to raise SCFAs in rats [100], while PCs of red wine and black tea reduced them [101]. These changes in SCFA generation could influence the cholesterol metabolism since acetate is the primary substrate for cholesterol synthesis [102], propionate is related to lipid metabolism [103], and butyrate reduces total cholesterol [64]. In a subsample of the VOHF study, ingestion of different VOOs did not affect the faecal quantities of propionic, acetic, and butyric acids [62]. Butyrate excretion in faeces of mice was increased after consumption of an OOPC extract-enriched diet in comparison with a control diet [104]. It has been reported that extra VOO consumption in hypertensive rats increases the cluster Clostridium $\mathrm{XIVa}$, a strict anaerobic group. This bacterial group includes butyrate producers, which has been linked to reductions in total cholesterol as previously mentioned [64]. In this regard, extra VOO is also 
associated to Clostridium cocleatum [11,31]. On the contrary, a borderline decrease of Clostridium cluster XI was observed after an OOPC-enriched VOO diet versus a nonenriched VOO diet, and no changes were observed in total cholesterol after this intervention [62]. Ruminococcus, from the order Clostridia, was decreased in relative abundance after consumption of olive-pomace enriched biscuits in mildly hypercholesterolemic humans [88]. Thus, an increase of butyrate or gut bacteria that produce butyrate has been observed after OOPC s consumption in various studies. However, the majority of these studies did not analyze total cholesterol. Therefore, studies measuring both parameters are needed to obtain clear conclusions regarding the effects of butyrate on cholesterol metabolism. Furthermore, not all studies disentangle the possible effects exerted by OOPCs or OO lipids.

In conclusion, the beneficial effects of OOPCs on lipid metabolism could be partially explained by gut microbiota changes induced by OOPCs. OOPCs increase Bacteroidetes or reduce the Firmicutes/ Bacteroidetes ratio, both associated with atheroprotection. Moreover, butyrate (which decreases cholesterol) or gut bacteria that produce butyrate increase after consumption of OOPCs. Finally, the increase of beneficial gut bacteria after consumption of OOPC such as Bifidobacteria, and in some cases Lactobacillus, could have a positive influence on lipid metabolism. Nevertheless, the relationship between oxidized LDL and Lactobacillus is heterogeneous across species, experimental setting, and host organism. Further clinical trials are needed to expand the knowledge on microbiota-OOPC-lipid homeostasis relationship.

In vivo studies which analyze the effect of OOPCs on microbiota and lipids at the same time are shown in Table 2.

\section{Effects of Olive Oil Phenolic Compounds on Gut Microbiota and Immune System}

The gut microbiome is extremely important in the development and maturation of a normal immune system. Diet can influence aspects of human biology by connecting nutrient metabolism, gut microbiota, and the immune system $[105,106]$. The gut microbiota contributes to the development of gut-associated lymphoid tissues (GALTs) which constitutes the most extensive and complex part of the immune system in the body), the polarization of gut-specific immune responses, and the prevention of colonization by pathogens. In turn, the composition of the microbiota is regulated by gut immune responses that are induced by commensal populations. Moreover, the alteration of the composition of the microbial composition and gut barrier function is observed in autoimmune and chronic inflammatory diseases $[107,108]$. As such, a lower Firmicutes/Bacteroidetes ratio in systemic lupus erythematosus patients has been described [109]. Conversely, Firmicutes are increased in rheumatoid arthritis [110] and Sjögren's syndrome patients [111]. Overall, the crosstalk between GALT and the microbiota is a complex and tightly regulated process, which has been shown to be critical for mucosal tissue homeostasis, maintenance of mucosal barrier function, and protection against infectious and mucosal inflammatory diseases [112]. Furthermore, low bacterial species diversity has also been associated with increased incidence of inflammatory phenotype [113].

VOO exerts anti-inflammatory and immunomodulatory activities partially due to its content in PCs [62,114-116]. Extra VOO PCs are absorbed, metabolized, and distributed in the blood stream throughout the body, being potentially useful agents in modulating local and systemic inflammatory environments in immune-mediated inflammatory diseases (IMID) [117]. For this reason, the capability of PCs has been worthy of consideration as potential agents in the IMID management [34,117].

Works exploring the anti-inflammatory activity of OOPCs together with its role in the immune system and in the prevention and treatment of IMID have been recently reviewed [118]. The effects of extra VOO and its PCs positively influence the expression of pro- and anti-inflammatory mediators involved in IMID by modulating specific signaling molecules and related transcription factors. VOO ingestion has been shown to decrease the levels of inflammatory markers such as IL-6 [119], visfatin [120], TNF- $\alpha$, IL-1 $\beta$, COX-2 in plasma [121], IFN- $\gamma$ in plasma and in the epididymal adipose tissue [122], TNF- $\alpha$, IL-6, and IL-17 in splenocytes [123] and IL-1, IL-3, IL-8, and COX-2 in peripheral blood mononuclear cells [124,125]. The beneficial effects of extra VOO intake might also include improving the anti-inflammatory and antioxidant defenses by increasing the expression of cytokines 
such as IL-10 [121], the activity of the antioxidant GPX enzyme [126], and the antioxidant transcription factor Nrf2 [127]. Similar results have been observed with dietary supplementation of single OOPC components such as oleuropein and its derivative HT [128-131], tyrosol [132], and oleocanthal [133]. In vitro studies have demonstrated that most of the crossinteracting signaling pathways activated in IMID appear to be modulated by VOO PCs $[124,134]$. Nevertheless, existing data is not enough to issue specific nutritional guidelines for immune-mediated diseases. Appropriate clinical and epidemiological studies are necessary to further evaluate the contribution of OOPCs in IMID management.

It is also of our interest to review studies that explore the effects of OOPCs consumption on the immune system by means of microbiota. In that sense, in a subsample of the VOHF study, it was investigated whether PCs influenced mucosal and systemic immunity. Hypercholesterolemic patients who ingested OO enriched with PC for three weeks presented higher IgA-coating bacteria and C-reactive protein (CRP) [112]. Reasonable explanations for these findings were either a change in the composition and metabolic output of gut bacteria or qualitative changes in species that would stimulate the production and secretion of IgA. However, the concomitant increase in plasma CRP seems inconsistent with the antioxidant and anti-inflammatory effects associated with OOPCs. It has been previously stated that high doses of exogenous antioxidant compounds may be toxic [135]. It is possible that the unusually high amount of PCs included in the OO consumption sustained for three weeks could be responsible for the unexpected effect in CRP. CRP levels have also been shown to raise when circadian rhythm is altered [136], in type-2 diabetes [137], and with dietary habits or fast/fed status [138], factors that might have contributed to the observed increase in CRP. Another randomized controlled trial which tested an OOPC-enriched VOO in pre-/hypertensive individuals in a postprandial situation, demonstrated that this treatment improved proinflammatory biomarkers such as VCAM-1 and PAI-1. However, this study did not examine the gut microbiota [139].

Fish oil and VOO consumption has also been proven effective on decreasing joint pain intensity and ameliorating clinical and laboratory parameters of rheumatoid arthritis [140]. Several other studies related to psoriasis have demonstrated an inverse association of disease severity and CPR levels following extra VOO consumption [141]. Improvement of psoriasis signs also followed application of herbal preparation containing high percentage of OO [142].

Some of the observed discrepancies among the studies could be explained by the different PC concentrations in VOOs, by the different healthy background of the included participants, or by the design of the clinical trial (long-term vs. acute). Further studies should be designed in order to address the controversy regarding the proinflammatory biomarkers.

Probiotics have been considered as adjuvant therapy for autoimmune diseases. Potential mechanisms supporting this include increased mucus secretion, antimicrobial peptide production, enhancement of the gastrointestinal-epithelial barrier function, and improvement of gut microbiota-mucosal immune cell crosstalk [143]. OOPCs act as potential prebiotics for the growth of certain colonic bacterial strains such as Lactobacillus and Bifidobacterium [33,62] and increase gut bacteria diversity, which is associated with healthier phenotypes. OOPCs could be protective for IMID since probiotics are beneficial for immune system and low bacterial species diversity has been associated with an inflammatory phenotype [113].

Furthermore, metabolites generated by gut microbiota are able to influence the immune system. Reduced butyrate has been found in IMID such as irritable bowel disease [144]. As previously stated, a number of studies demonstrated that PCs can modulate gut microbiota composition as well as their SCFA production. Concretely, increased butyrate or gut bacteria which produces butyrate has been observed after PCs and OOPCs consumption in various studies $[64,104]$. Moreover, irritable bowel disease patients have increased Fusobacterium, Escherichia, and Proteobacteria and decreased Bacteroides, Bifidobacterium, and Clostridium groups IV and XIVA. Several meta-analysis and cohort studies have demonstrated that fecal microbiota transplantation improves the bowel movement in affected patients and colitis animal models [145-148]. OOPC could also be beneficial in these patients since they increase Bacteroidetes and Bifidobacterium $[62,66,67]$. 
In conclusion, some immune disorders are characterized by low bacterial species diversity and low levels of butyrate. OOPCs could be a potential nutritional tool to improve the inflammatory status since they increase gut-bacteria diversity, butyrate concentrations, and beneficial microbes. Clinical trials in IMID patients are needed to confirm these hypotheses.

In vivo studies which analyze the effect of OOPCs on microbiota and the immune system at the same time are shown in Table 2.

\section{Effects of Olive Oil Phenolic Compounds on Gut Microbiota and Obesity and Associated Morbidities}

Obesity is a complex, multifaceted medical condition in which body fat accumulates in adipose tissue and throughout the body, with individuals exceeding a BMI of $>30 \mathrm{~kg} / \mathrm{m} 2$ being considered as obese. This chronic condition is often associated with several harmful comorbidities, such as Type 2 diabetes, nonalcoholic fatty liver disease, cardiovascular and neurodegenerative diseases, and several types of cancer $[149,150]$. The intestinal microbiota has been identified to be a potentially important player in the development, exacerbation, and/or alleviation of obesity and related comorbidities. Dietary PCs have been associated with palliating symptoms of obesity and related conditions such as metabolic syndrome. Multiple studies have shown a negative association between PC consumption and weight gain [151]. PCs from green tea, mainly epigallocatechin gallate, caffeoylquinic acid, grape seed proanthocyanidins, resveratrol from grapes or wine, anthocyanins and other flavonoids have also been inversely associated with both BMI and other clinical markers of metabolic syndrome [152]. Several studies found that weight gain, waist circumference, and blood pressure decreased after extra VOO consumption, in contrast with other vegetable oils [153]. Oleuropein, a phenolic acid found in VOO, has been characterized as having antidiabetic, antiatherosclerotic, and anti-inflammatory properties in humans [6]. HT, the main OOPC, downregulated the expression of PPAR- $\alpha$ and PPAR- $\gamma$, leading to a reduction in adipocyte size in in vitro studies $[154,155]$. HT could modulate inflamed human adipocyte gene expression by regulating the microRNAs miR-155-5p, miR-34a-5p, and let-7c-5p expression, leading to a reduction of oxidative stress and NF-k $\beta$ inhibition [156], which is a key pathway involved in systemic inflammation in obesity. HT also improves inflammation, insulin resistance, and hepatic steatosis by reducing endoplasmic reticulum stress and by regulating the JNK/IRS pathway in high-fat diet-induced obese mice [157]. Other mechanisms have been proposed for the antiobesogenic effects of PCs, including reducing nutrient intake by the gastrointestinal tract through digestive enzyme inhibition, reduced adipogenesis, alteration of glucose homeostasis, promotion of fat oxidation, and increasing energy expenditure via increased thermogenesis (reviewed in $[151,158])$. The gut microbiota has been shown to participate in increasing energy extraction and fat deposition in the host [159], as well as modulate host metabolism, inflammatory status, gut barrier integrity, and satiety [160]. Efforts to identify a specific gut microbiota taxonomic signature associated with the development of obesity have revealed large interindividual differences [161], although a core microbiome, or enterotype, has been associated with lean phenotypes. Deviations to this core, a dysbiosis, may be found in conditions such as obesity [162]. Initial studies on the composition of the gut microbiota in the obese phenotype indicated an increased ratio of the bacterial phyla Firmicutes/Bacteroidetes [14,163], although other studies have either not observed this trend or even observed opposite trends [72,164,165]. Effects of OOPCs on the Firmicutes/Bacteroidetes ratio are limited, as only a few studies have shown that administration of purified caffeic acid and ferulic acid, which are minor components of PC in extra VOO, reduce this ratio in mice $[66,67]$. However, other major PCs present in VOO, such as HT, showed no differences in this ratio [65]. Reduced bacterial species diversity and richness in the gut microbiota have also been associated with obesity [162,166,167], although there is also some evidence of increased diversity in at least some obese patients [168]. Low bacterial species diversity has also been associated with increased incidence of adiposity and insulin resistance [169]. Positive effects of OOPC administration on increasing microbial diversity have been observed in rodents, as previously stated. In high-fat diet-induced obese mice, the supplementation of HT restored 
microbial diversity back to comparable levels with the control group fed a standard chow diet [65]. In a recent study, mice fed a high-fat diet supplemented with either extra VOO or flaxseed oil, displayed significantly higher microbial diversity, as compared to mice fed a high-fat diet without these supplements [170]. However, it is unclear in this study whether these beneficial effects were directly attributable to the lipids or PCs present in the VOO.

OOPCs can also serve as prebiotics for the growth of certain beneficial colonic bacteria such as Lactobacillus and Bifidobacterium [33], both of which are bacterial genera with potential antiobesity effects [171,172]. Furthermore, several OOPCs have been shown to stimulate the growth of SCFA-producing bacteria as well as increase the production of SCFAs, as previously indicated. SCFAs are produced by gut microbiota fermentation of specific dietary sources, such as different types of indigestible fiber, which have recently been implicated in influencing host appetite and food intake [173]. SCFAs (primarily butyrate) interact with enteroendocrine cells via communication between the so called gut-brain axis to produce paracrine and/or endocrine signaling via glucagon-like peptide-1, cholecystokinin, peptide YY3-36, pancreatic polypeptide, and oxyntomodulin $[173,174]$. Furthermore, propionate, another important SCFA produced by gut microbiota in the colon, increases intestinal gluconeogenesis which increases satiety and improves glucose homeostasis [175]. PCs, including HT, resveratrol and anthocyanins are also known to stimulate the enzyme $5^{\prime}$ AMP-activated protein kinase, which is involved in regulating cellular energy homeostasis [158], possibly via an interaction with the gut microbiota to promote production of SCFAs [176]. Additionally, an increase in the enzyme $5^{\prime}$ AMP-activated protein kinase and hormone-sensitive lipase and phosphorylated lipase was observed in adipocytes exposed to HT [68]. It is important to note that although there is a large amount of evidence of beneficial effects of butyrate on alleviating diet-induced obesity and insulin resistance, human observational studies have also shown higher amounts of fecal excretion of SCFAs in obese subjects $[164,177,178]$ and increased excreted SCFAs with consumption of high calorie diets [179]. SCFAs could therefore also contribute to adiposity by providing a substantial amount $(10 \%)$ of the daily energy requirement in humans [180]. These factors complicate the role of SCFAs in diet-induced obesity and thus warrant more studies.

Obesity is often characterized by low grade intestinal inflammation caused by increased permeability of the intestinal epithelium, which can lead to the passage of microbially-derived compounds such as LPS into circulation, thereby causing metabolic endotoxaemia, and inflammatory disorders [181]. Related with intestinal inflammation, hydroxytyrosyl acetate (HT-Ac), also present in VOO, has been reported to exhibit gut anti-inflammatory effects [33] in DSS-induced acute colitis in mice [182].

Both the gut microbiota and PCs have been demonstrated to play roles in modulating the intestinal barrier. For instance, changes in intestinal gut microbiota caused by high-fat Western diets cause decreased production of SCFAs, host antimicrobial peptides, mucus production, and tight-junction production, which all lead to the increased intestinal permeability observed in obesity $[181,183]$. OOPCs contribute to maintaining gut barrier integrity by upregulating the expression of genes involved in maintaining tight junctions between intestinal cells, modulating the oxidative status of the intestinal epithelial layer, as well as the inflammatory and immune response $[23,170]$. Administration of HT to high-fat diet-induced obese mice showed increased gene expression for the tight junction associated proteins ZO-1 and occludin, as well as reduced levels of plasma LPS and inflammatory cytokines in the liver, all supporting a role for HT in promoting intestinal barrier integrity [65]. 
Table 2. In vivo studies assessing the effects of OOPC on gut microbiota, lipid metabolism, immune system, and obesity and associated morbidities.

\begin{tabular}{|c|c|c|c|c|c|}
\hline \multicolumn{6}{|c|}{ OOPC on Lipid Metabolism and Gut Microbiota } \\
\hline Treatments & Duration & $\begin{array}{c}\text { Animal Model or } \\
\text { Patients' Health Status }\end{array}$ & $N$ & OOPC Effects & Reference \\
\hline $\begin{array}{l}\text {-Olive-pomace enriched biscuits (90 g) (1) } \\
\text {-Isoenergetic control (2) }\end{array}$ & $\begin{array}{c}8 \text { weeks } \\
\text { Randomized } \\
\text { Controlled } \\
\text { Parallel } \\
\text { Double-blind }\end{array}$ & $\begin{array}{l}\text { Hypercholesterolemic } \\
\text { patients }\end{array}$ & $62(1=34 ; 2=28)$ & $\begin{array}{c}\text { Olive-pomace enriched biscuits: } \\
\downarrow \text { oxidized LDL } \\
\downarrow \text { Lactobacillus } \\
\downarrow \text { Ruminococcus } \\
=\text { gut microbiota diversity }\end{array}$ & [88] \\
\hline $\begin{array}{l}\text {-Extra VOO (1) } \\
\text {-Enriched butter diet (2) } \\
\text {-Standard diet (3) }\end{array}$ & 12 weeks & Mice & $26(1=9 ; 2=9 ; 3=8)$ & $\begin{array}{c}\text { Extra VOO: } \\
\downarrow \text { Desulfovibrio } \\
\uparrow \text { Sutterellaceae } \\
\uparrow \text { Marispirillum } \\
\uparrow M u c i l a g i n i b a c t e r \text { dageonensis } \\
=\text { lipids }\end{array}$ & [87] \\
\hline $\begin{array}{l}\text {-VOO enriched with OOPC and thyme PC } \\
\quad(500 \mathrm{mg} / \mathrm{kg} \text { PC) } \\
\text {-VOO enriched with OOPC ( } 500 \mathrm{mg} / \mathrm{kg} \mathrm{PC}) \\
\text {-VOO }\end{array}$ & $\begin{array}{l}3 \text { weeks }(25 \mathrm{~mL} / \text { day }) \\
\text { Randomized } \\
\text { Controlled } \\
\text { Crossover } \\
\text { Double-blind }\end{array}$ & $\begin{array}{l}\text { Hypercholesterolemic } \\
\text { patients }\end{array}$ & 12 & $\begin{array}{c}\text { VOO enriched with OOPC and thyme PC: } \\
\uparrow \text { Bifidobacteria } \\
\uparrow \text { Parascardovia } \\
\uparrow \text { protocateuchuic acid } \\
\downarrow \text { oxidized LDL } \\
\text { VOO enriched with OOPC: } \\
\downarrow \text { Clostridium cluster XI (borderline) } \\
\uparrow \text { coprostanone } \\
=\text { total cholesterol }\end{array}$ & [62] \\
\hline \multicolumn{6}{|c|}{ OOPC on Immune System and Gut Microbiota } \\
\hline Treatment & Duration & $\begin{array}{l}\text { Animal Model OR } \\
\text { Patients' Health Status }\end{array}$ & $N$ & OOPC Effects & Reference \\
\hline $\begin{array}{c}\text {-VOO enriched with OOPC and thyme PC } \\
\text { (500 mg/kg phenolics) } \\
\text {-VOO enriched with OOPC } \\
\text { (500 mg/kg phenolics) } \\
\text {-VOO }\end{array}$ & $\begin{array}{l}3 \text { weeks }(25 \mathrm{~mL} / \text { day }) \\
\text { Randomized } \\
\text { Controlled } \\
\text { Crossover } \\
\text { Double-blind }\end{array}$ & $\begin{array}{l}\text { Hypercholesterolemic } \\
\text { patients }\end{array}$ & 10 & 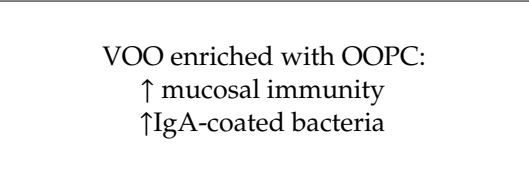 & [62] \\
\hline \multicolumn{6}{|c|}{ OOPC on Obesity and Associated Morbidities, and Gut Microbiota } \\
\hline Treatment & Duration & $\begin{array}{c}\text { Animal Model or } \\
\text { Patients' Health Status }\end{array}$ & $N$ & OOPC Effects & Reference \\
\hline $\begin{array}{c}\text {-Normal fat diet (control) } \\
\text {-Ferulic acid ( } 30 \mathrm{mg} / \mathrm{kg} / \text { day }) \\
\text {-Simvastatin }(5 \mathrm{mg} / \mathrm{kg} / \text { day }) \\
\text {-Normal saline }\end{array}$ & 12 weeks & $\begin{array}{c}\mathrm{ApoE}^{-/-} \text {mice fed high-fat } \\
\text { diets (male) }\end{array}$ & 20 (5/group) & $\begin{array}{c}\text { Ferulic acid: } \\
\uparrow \text { serum TC, TG, and LDL-C } \\
\uparrow \alpha \text { diversity } \\
\downarrow \text { Firmicutes/Bacteroidetes }\end{array}$ & [67] \\
\hline
\end{tabular}


Table 2. Cont.

\begin{tabular}{|c|c|c|c|c|c|}
\hline \multicolumn{6}{|c|}{ OOPC on Obesity and Associated Morbidities, and Gut Microbiota } \\
\hline Treatment & Duration & $\begin{array}{c}\text { Animal Model or } \\
\text { Patients' Health Status }\end{array}$ & $N$ & OOPC Effects & Reference \\
\hline $\begin{array}{l}\text {-High-fat extra-VOO } \\
\text {-High-fat flaxseed oil } \\
\text {-Low-fat } \\
\text {-Lard }\end{array}$ & 10 weeks & C57BL/6 J mice & 20 (5/group) & $\begin{array}{c}\text { High-fat extra-VOO: } \\
\uparrow \text { gut microbiota diversity } \\
\downarrow \text { Firmicutes } \\
\uparrow \text { FoxP3 and IL-10 } \\
\uparrow \text { antimicrobial peptide RegIII }\end{array}$ & [170] \\
\hline $\begin{array}{c}\text {-PBS } \\
\text {-Fine particular matter } \\
\text {-Fine particular matter suspended in PBS } \\
(1 \mathrm{mg} / \mathrm{mL})+\text { HT }(50 \mathrm{mg} / \mathrm{kg} / \text { day })\end{array}$ & 4 weeks & C57BL/6 J mice (female) & 45 (15/group) & $\begin{array}{c}\text { Fine particular matter }+\mathrm{HT}: \\
\downarrow \text { visceral adipogenesis } \\
\downarrow \text { oxidative stress } \\
\downarrow \text { hepatic inflammation } \\
\downarrow N F-\kappa \beta \text { activation } \\
\downarrow \text { insulin resistance } \\
\uparrow \text { gut microbiota richness } \\
\downarrow \text { pathogenic bacteria }\end{array}$ & {$[68]$} \\
\hline $\begin{array}{c}\text {-HT (+high fat diet) } \\
\text {-HT fecal microbiota transplantation } \\
\text { (+high fat diet) } \\
\text {-High fat diet } \\
\text {-Control (chow diet) }\end{array}$ & 8 weeks & C57BL/6 J mice (male) & 28 (7/group) & $\begin{array}{c}\text { HT and HT fecal microbiota } \\
\text { transplantation: } \\
\downarrow \text { altered intestinal microbiota } \\
\uparrow \text { intestinal barrier function } \\
\downarrow \text { endotoxin release } \\
\downarrow \mathrm{TNF}-\alpha, \text { IL-1 } \beta \text {, and IL-6 } \\
\downarrow \text { lipid accumulation in liver } \\
=\text { Firmicutes/Bacteroidetes } \\
\downarrow \text { Proteobacteria } \\
\downarrow \text { Deferribacteres }\end{array}$ & [65] \\
\hline $\begin{array}{c}\text {-Control } \\
\text {-Water containing 2.5\% DSS } \\
\text {-Water containing } 2.5 \% \text { DSS + Caffeic acid } \\
(1 \mathrm{mM})\end{array}$ & $\begin{array}{l}\text {-DSS: } 8 \text { days } \\
\text {-Caffeic acid: } 15 \text { days }\end{array}$ & $\begin{array}{l}\text { Mice (control, DSS, } \\
\text { DSS+caffeic acid) }\end{array}$ & 30 (10/group) & $\begin{array}{c}\text { Caffeic acid (in DSS colitis mice): } \\
\downarrow \text { secretion of IL-6 } \\
\downarrow \text { TNF } \alpha \\
\downarrow \text { IFN } \gamma \\
\downarrow \text { colonic infiltration of CD3 }{ }^{+} \mathrm{T} \text { cells, } \\
\text { CD177 }{ }^{+} \text {neutrophils, } \mathrm{F} 4 / 80^{+} \text {macrophages } \\
\uparrow \text { species richness } \\
\uparrow \text { Akkermansia } \\
\downarrow \text { Firmicutes/Bacteroidetes }\end{array}$ & [66] \\
\hline
\end{tabular}

CD, cluster of differentiation; FoxP3, forkhead box P3; HT, hydroxytyrosol; IFN, interferon; IL, interleukin; LDL-c, low-density lipoprotein cholesterol; NF, Necrosis factor; OOPC, olive oil phenolic compounds; TC, total cholesterol; TG, triglycerides; VOO, virgin olive oil; $\downarrow$, decrease; $\uparrow$, increase; =, no changes. 
Akkermansia muciniphila, a mucin-degrading bacterium that is highly prevalent in healthy humans in the mucus layer covering the intestinal epithelium, is well-known for its inverse association with obesity, diabetes, and inflammation [151]. Furthermore, A. muciniphila treatment in mice reverses high-fat diet-induced metabolic endotoxemia, adipose tissue inflammation, and insulin resistance, restoring mucus thickness [184]. Pasteurized A. muciniphila treatment in humans improved insulin sensitivity, reduced plasma total cholesterol and blood markers of liver dysfunction and inflammation, and slightly decreased body weight [185]. In ulcerative colitis mouse models, administration of caffeic acid, present in VOO, was shown to reduce colonic infiltration of T-cells, neutrophils and proinflammatory cytokines, restoring the species richness and drastically increasing the proportion of Akkermansia [66]. Increased growth of A. muciniphila has also been associated with the consumption of prebiotic fructo-oligosaccharides, as well as certain dietary PCs found in black tea, red wine grape extracts, cranberry extracts, and other berries $[151,186]$. Although the exact mechanism behind this increase in A. muciniphila from PCs is unclear, it could be a result of an increase in the production of mucus is observed after PC administration, which could provide a major energy source for the bacterium [187]. Furthermore, the antioxidant properties of PCs could further propagate the anaerobic conditions required for successful growth of this bacterium [188].

In conclusion, evidence from in vitro and preclinical studies has demonstrated that OOPCs could be a potential nutritional tool to modulate the gut microbiome by increasing microorganism diversity and beneficial bacteria in obesity. However, nutritional clinical trials specifically designed to avoid confounder dietary factors in obese patients are needed to confirm these hypotheses. Moreover, many microbial metabolites such as SCFAs remain unidentified and their roles in obesity remain to be elucidated. Future investigations to address a causal relationship and the underlying mechanism in the gut microbiome and diet interaction with a particular emphasis on the development of microbiome-targeted therapies for obesity prevention and treatment are needed.

In vivo studies which analyze the effect of OOPCs on microbiota and obesity are shown in Table 2.

\section{Conclusions}

Overall, strong evidence suggesting a link between OOPCs, the gut microbiota, and their derived metabolites exists. Although many studies have been performed in vitro using faecal slurries or cultured bacteria, evidence suggests that OOPCs modulate microbial composition and metabolism and increase the diversity of the gut bacterial communities producing beneficial effects. Specifically, the consumption of OOPCs produces an increase of Bacteroidetes or a reduction of Firmicutes/Bacteroidetes, which is associated with atheroprotection. The observed increase in beneficial bacteria such as Bifidobacteria, and in some cases Lactobacillus, after OOPC administration could also have positive effects on atherosclerosis, immune disorders, and obesity. OOPC antimicrobial activity, bacterial cholesterol metabolism, and the different metabolites produced by bacteria are some of the factors and mechanisms implicated in these effects. Specifically, the consumption of OOPCs changes the SCFAs' production by gut bacteria. SCFAs are involved in cholesterol metabolism, immune system regulation, and may play a role in weight gain in obesity through promoting satiety (Scheme 1). Despite the strong experimental evidence already accumulated, data from large-scale, long-term randomized clinical trials is still scarce. Furthermore, before conducting these clinical trials, it could be of interest to perform experiments with fecal microbiota transplantation in animal models in order to acquire relevant information regarding the restore of gut microbiota in each specific disorder. If successful, clinical trials designed to assess the specific role of the OOPCs in the above mentioned areas may provide the information needed for the development of new nutritional guidelines. These clinical trials should also clarify if it would be better to administer OOPCs alone with capsules or with a VOO matrix. 


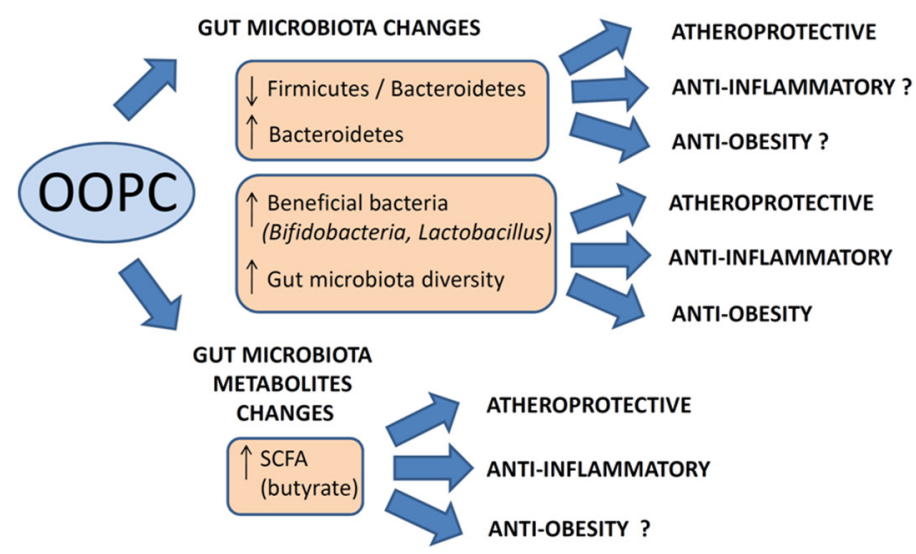

Scheme 1. Effects of OOPC on gut microbiota and the implications for lipid metabolism, immune system, and obesity.

Supplementary Materials: The following are available online at http://www.mdpi.com/2072-6643/12/8/2200/s1, Table S1: Results from PREDIMED study on lipid metabolism, immune system, and obesity.

Author Contributions: M.F., M.T. and F.B.-V. conceptualization; M.F. methodology; M.F. software; M.F. validation; M.F. formal analysis; M.F., L.M-.G., K.P., S.A. and M.T. investigation; M.F., M.T., F.B.-V. resources; M.F., M.T. data curation; M.F., L.M.-G., K.P. and M.T. writing—original draft preparation; M.F., L.M.-G., S.A., G.F., M.T. and F.B.-V. writing-review and editing; M.F. visualization; M.F., M.T. and F.B.-V. supervision; M.F. project administration; M.F., G.F., M.T. and F.B.-V. funding acquisition. All authors have read and agreed to the published version of the manuscript.

Funding: This work was funded by the Instituto de Salud Carlos III and FEDER "Una manera de hacer Europa", grant numbers: FIS PI1800164 (to M.T and F.B-V) and Sara Borrell contract CD17/00233 (to M.F). CIBERDEM is an Instituto de Salud Carlos III project. This work was also financially supported by the Centre for the Development of Industrial Technology (CDTI) of the Spanish Ministry of Science and Innovation under the grant agreement: TECNOMIFOOD project. CER-20191010. L.M-G is supported by the NIHR Imperial Biomedical Research Centre (BRC).

Acknowledgments: We thank Joan Carles Escolà-Gil for their help in editing text.

Conflicts of Interest: The authors declare no conflict of interest.

\section{References}

1. Dinu, M.; Pagliai, G.; Casini, A.; Sofi, F. Mediterranean diet and multiple health outcomes: An umbrella review of meta-analyses of observational studies and randomised trials. Eur. J. Clin. Nutr. 2018, 72, 30-43. [CrossRef]

2. Martinez-Gonzalez, M.A.; Ros, E.; Estruch, R. Primary Prevention of Cardiovascular Disease with a Mediterranean Diet Supplemented with Extra-Virgin Olive Oil or Nuts. N. Engl. J. Med. 2018, 379, 1388-1389. [CrossRef] [PubMed]

3. Fito, M.; Estruch, R.; Salas-Salvado, J.; Martinez-Gonzalez, M.A.; Aros, F.; Vila, J.; Corella, D.; Diaz, O.; Saez, G.; de la Torre, R.; et al. Effect of the Mediterranean diet on heart failure biomarkers: A randomized sample from the PREDIMED trial. Eur. J. Heart Fail. 2014, 16, 543-550. [CrossRef] [PubMed]

4. Martin-Pelaez, S.; Castaner, O.; Konstantinidou, V.; Subirana, I.; Munoz-Aguayo, D.; Blanchart, G.; Gaixas, S.; de la Torre, R.; Farre, M.; Saez, G.T.; et al. Effect of olive oil phenolic compounds on the expression of blood pressure-related genes in healthy individuals. Eur. J. Nutr. 2017, 56, 663-670. [CrossRef]

5. Piroddi, M.; Albini, A.; Fabiani, R.; Giovannelli, L.; Luceri, C.; Natella, F.; Rosignoli, P.; Rossi, T.; Taticchi, A.; Servili, M.; et al. Nutrigenomics of extra-virgin olive oil: A review. BioFactors 2017, 43, 17-41. [CrossRef]

6. Covas, M.I.; Nyyssonen, K.; Poulsen, H.E.; Kaikkonen, J.; Zunft, H.J.; Kiesewetter, H.; Gaddi, A.; de la Torre, R.; Mursu, J.; Baumler, H.; et al. The effect of polyphenols in olive oil on heart disease risk factors: A randomized trial. Ann. Intern. Med. 2006, 145, 333-341. [CrossRef] 
7. Farras, M.; Valls, R.M.; Fernandez-Castillejo, S.; Giralt, M.; Sola, R.; Subirana, I.; Motilva, M.J.; Konstantinidou, V.; Covas, M.I.; Fito, M. Olive oil polyphenols enhance the expression of cholesterol efflux related genes in vivo in humans. A randomized controlled trial. J. Nutr. Biochem. 2013, 24, 1334-1339. [CrossRef]

8. Valls, R.M.; Farràs, M.; Pedret, A.; Fernández-Castillejo, S.; Catalán, Ú.; Romeu, M.; Giralt, M.; Sáez, G.T.; Fitó, M.; De la Torre, R.; et al. Virgin olive oil enriched with its own phenolic compounds or complemented with thyme improves endothelial function: The potential role of plasmatic fat-soluble vitamins. A double blind, randomized, controlled, cross-over clinical trial. J. Funct. Foods 2017, 28, 285-292. [CrossRef]

9. Pedret, A.; Fernandez-Castillejo, S.; Valls, R.M.; Catalan, U.; Rubio, L.; Romeu, M.; Macia, A.; Lopez de Las Hazas, M.C.; Farras, M.; Giralt, M.; et al. Cardiovascular Benefits of Phenol-Enriched Virgin Olive Oils: New Insights from the Virgin Olive Oil and HDL Functionality (VOHF) Study. Mol. Nutr. Food Res. 2018, 62, e1800456. [CrossRef]

10. Tang, W.H.; Kitai, T.; Hazen, S.L. Gut Microbiota in Cardiovascular Health and Disease. Circ. Res. 2017, 120, 1183-1196. [CrossRef]

11. Arumugam, M.; Raes, J.; Pelletier, E.; Le Paslier, D.; Yamada, T.; Mende, D.R.; Fernandes, G.R.; Tap, J.; Bruls, T.; Batto, J.M.; et al. Enterotypes of the human gut microbiome. Nature 2011, 473, 174-180. [CrossRef]

12. Faith, J.J.; McNulty, N.P.; Rey, F.E.; Gordon, J.I. Predicting a human gut microbiota's response to diet in gnotobiotic mice. Science 2011, 333, 101-104. [CrossRef]

13. Scott, K.P.; Gratz, S.W.; Sheridan, P.O.; Flint, H.J.; Duncan, S.H. The influence of diet on the gut microbiota. Pharmacol. Res. 2013, 69, 52-60. [CrossRef]

14. Ley, R.E.; Backhed, F.; Turnbaugh, P.; Lozupone, C.A.; Knight, R.D.; Gordon, J.I. Obesity alters gut microbial ecology. Proc. Natl. Acad. Sci. USA 2005, 102, 11070-11075. [CrossRef]

15. Rial, S.A.; Karelis, A.D.; Bergeron, K.F.; Mounier, C. Gut Microbiota and Metabolic Health: The Potential Beneficial Effects of a Medium Chain Triglyceride Diet in Obese Individuals. Nutrients 2016, 8, 281. [CrossRef]

16. Telle-Hansen, V.H.; Holven, K.B.; Ulven, S.M. Impact of a Healthy Dietary Pattern on Gut Microbiota and Systemic Inflammation in Humans. Nutrients 2018, 10, 1783. [CrossRef]

17. Skrypnik, K.; Bogdanski, P.; Loniewski, I.; Regula, J.; Suliburska, J. Effect of probiotic supplementation on liver function and lipid status in rats. Acta Sci. Pol. Technol. Aliment. 2018, 17, 185-192. [CrossRef]

18. Tomas-Barberan, F.A.; Selma, M.V.; Espin, J.C. Interactions of gut microbiota with dietary polyphenols and consequences to human health. Curr. Opin. Clin. Nutr. Metab. Care 2016, 19, 471-476. [CrossRef]

19. Eckburg, P.B.; Bik, E.M.; Bernstein, C.N.; Purdom, E.; Dethlefsen, L.; Sargent, M.; Gill, S.R.; Nelson, K.E.; Relman, D.A. Diversity of the human intestinal microbial flora. Science 2005, 308, 1635-1638. [CrossRef]

20. Donaldson, G.P.; Lee, S.M.; Mazmanian, S.K. Gut biogeography of the bacterial microbiota. Nat. Rev. Microbiol. 2016, 14, 20-32. [CrossRef]

21. Sender, R.; Fuchs, S.; Milo, R. Revised Estimates for the Number of Human and Bacteria Cells in the Body. PLoS Biol. 2016, 14, e1002533. [CrossRef] [PubMed]

22. Zhernakova, A.; Kurilshikov, A.; Bonder, M.J.; Tigchelaar, E.F.; Schirmer, M.; Vatanen, T.; Mujagic, Z.; Vila, A.V.; Falony, G.; Vieira-Silva, S.; et al. Population-based metagenomics analysis reveals markers for gut microbiome composition and diversity. Science 2016, 352, 565-569. [CrossRef] [PubMed]

23. Deiana, M.; Serra, G.; Corona, G. Modulation of intestinal epithelium homeostasis by extra virgin olive oil phenolic compounds. Food Funct. 2018, 9, 4085-4099. [CrossRef] [PubMed]

24. Jie, Z.; Xia, H.; Zhong, S.L.; Feng, Q.; Li, S.; Liang, S.; Zhong, H.; Liu, Z.; Gao, Y.; Zhao, H.; et al. The gut microbiome in atherosclerotic cardiovascular disease. Nat. Commun. 2017, 8, 845. [CrossRef] [PubMed]

25. Rooks, M.G.; Garrett, W.S. Gut microbiota, metabolites and host immunity. Nat. Rev. Immunol. 2016, 16, 341-352. [CrossRef]

26. Abdul Rahim, M.B.H.; Chilloux, J.; Martinez-Gili, L.; Neves, A.L.; Myridakis, A.; Gooderham, N.; Dumas, M.E. Diet-induced metabolic changes of the human gut microbiome: Importance of short-chain fatty acids, methylamines and indoles. Acta Diabetol. 2019, 56, 493-500. [CrossRef]

27. Canyelles, M.; Tondo, M.; Cedo, L.; Farras, M.; Escola-Gil, J.C.; Blanco-Vaca, F. Trimethylamine N-Oxide: A Link among Diet, Gut Microbiota, Gene Regulation of Liver and Intestine Cholesterol Homeostasis and HDL Function. Int. J. Mol. Sci. 2018, 19, 3228. [CrossRef]

28. Donini, L.M.; Serra-Majem, L.; Bullo, M.; Gil, A.; Salas-Salvado, J. The Mediterranean diet: Culture, health and science. Br. J. Nutr. 2015, 113 (Suppl. 2), S1-S3. [CrossRef] 
29. Soler-Rivas, C.; Espín, J.C.; Wichers, H.J. Oleuropein and related compounds. J. Sci. Food Agric. 2000, 80, 1013-1023. [CrossRef]

30. EFSA Panel on Dietetic Products. Nutrition and allergies, N. The Effect of Polyphenols in Olive Oil on Heart Diseases. EFSA J. 2011, 9, 2033.

31. Priore, P.; Caruso, D.; Siculella, L.; Gnoni, G.V. Rapid down-regulation of hepatic lipid metabolism by phenolic fraction from extra virgin olive oil. Eur. J. Nutr. 2015, 54, 823-833. [CrossRef] [PubMed]

32. Farras, M.; Castaner, O.; Martin-Pelaez, S.; Hernaez, A.; Schroder, H.; Subirana, I.; Munoz-Aguayo, D.; Gaixas, S.; Torre Rde, L.; Farre, M.; et al. Complementary phenol-enriched olive oil improves HDL characteristics in hypercholesterolemic subjects. A randomized, double-blind, crossover, controlled trial. The VOHF study. Mol. Nutr. Food Res. 2015, 59, 1758-1770. [CrossRef] [PubMed]

33. Corona, G.; Tzounis, X.; Assunta Dessi, M.; Deiana, M.; Debnam, E.S.; Visioli, F.; Spencer, J.P. The fate of olive oil polyphenols in the gastrointestinal tract: Implications of gastric and colonic microflora-dependent biotransformation. Free Radic. Res. 2006, 40, 647-658. [CrossRef] [PubMed]

34. Mosele, J.I.; Martin-Pelaez, S.; Macia, A.; Farras, M.; Valls, R.M.; Catalan, U.; Motilva, M.J. Faecal microbial metabolism of olive oil phenolic compounds: In vitro and in vivo approaches. Mol. Nutr. Food Res. 2014, 58, 1809-1819. [CrossRef] [PubMed]

35. Santos, M.M.; Piccirillo, C.; Castro, P.M.; Kalogerakis, N.; Pintado, M.E. Bioconversion of oleuropein to hydroxytyrosol by lactic acid bacteria. World J. Microbiol. Biotechnol. 2012, 28, 2435-2440. [CrossRef]

36. 36. Landete, J.M.; Curiel, J.A.; Rodríguez, H.; de las Rivas, B.; Muñoz, R. Study of the inhibitory activity of phenolic compounds found in olive products and their degradation by Lactobacillus plantarum strains. Food Chem. 2008, 107, 320-326. [CrossRef]

37. Cavin, J.F.B.L.; Guzzo, J.; Van Beeumen, J.; Samyn, B.; Travers, J.F.; Divieés, C. Purification and characterization of an inducible p-coumaric acid decarboxylase from Lactobacillus plantarum. FEMS Microbiol. Lett. 1997, 147, 291-295. [CrossRef]

38. Cavin, J.F.A.V.; Etievant, X.; Divies, C. Ability of Wine Lactic Acid Bacteria to Metabolize Phenol Carboxylic Acids. Am. J. Enol. Vitic. 1993, 40, 76-80.

39. Hanske, L.; Loh, G.; Sczesny, S.; Blaut, M.; Braune, A. The bioavailability of apigenin-7-glucoside is influenced by human intestinal microbiota in rats. J. Nutr. 2009, 139, 1095-1102. [CrossRef]

40. Lin, W.; Wang, W.; Yang, H.; Wang, D.; Ling, W. Influence of Intestinal Microbiota on the Catabolism of Flavonoids in Mice. J. Food Sci. 2016, 81, H3026-H3034. [CrossRef]

41. Schoefer, L.; Mohan, R.; Schwiertz, A.; Braune, A.; Blaut, M. Anaerobic degradation of flavonoids by Clostridium orbiscindens. Appl. Environ. Microbiol. 2003, 69, 5849-5854. [CrossRef] [PubMed]

42. Braune, A.; Blaut, M. Deglycosylation of puerarin and other aromatic C-glucosides by a newly isolated human intestinal bacterium. Environ. Microbiol. 2011, 13, 482-494. [CrossRef] [PubMed]

43. Peppercorn, M.A.; Goldman, P. Caffeic acid metabolism by bacteria of the human gastrointestinal tract. J. Bacteriol. 1971, 108, 996-1000. [CrossRef] [PubMed]

44. Gonthier, M.P.; Remesy, C.; Scalbert, A.; Cheynier, V.; Souquet, J.M.; Poutanen, K.; Aura, A.M. Microbial metabolism of caffeic acid and its esters chlorogenic and caftaric acids by human faecal microbiota in vitro. Biomed. Pharmacother. Biomed. Pharmacother. 2006, 60, 536-540. [CrossRef] [PubMed]

45. Ludwig, I.A.; Paz de Pena, M.; Concepcion, C.; Alan, C. Catabolism of coffee chlorogenic acids by human colonic microbiota. BioFactors 2013, 39, 623-632. [CrossRef]

46. Li, Y.; Zhou, G.; Peng, Y.; Tu, P.; Li, X. Screening and identification of three typical phenylethanoid glycosides metabolites from CistanchesHerba by human intestinal bacteria using UPLC/Q-TOF-MS. J. Pharm. Biomed. Anal. 2016, 118, 167-176. [CrossRef]

47. Xie, L.H.; Akao, T.; Hamasaki, K.; Deyama, T.; Hattori, M. Biotransformation of pinoresinoldiglucoside to mammalian lignans by human intestinal microflora, and isolation of Enterococcus faecalis strain PDG-1 responsible for the transformation of (+)-pinoresinol to (+)-lariciresinol. Chem. Pharm. Bull. 2003, 51, 508-515. [CrossRef]

48. Clavel, T.; Borrmann, D.; Braune, A.; Dore, J.; Blaut, M. Occurrence and activity of human intestinal bacteria involved in the conversion of dietary lignans. Anaerobe 2006, 12, 140-147. [CrossRef]

49. Esteban-Torres, M.; Santamaria, L.; Cabrera-Rubio, R.; Plaza-Vinuesa, L.; Crispie, F.; de Las Rivas, B.; Cotter, P.; Munoz, R. A Diverse Range of Human Gut Bacteria Have the Potential To Metabolize the Dietary Component Gallic Acid. Appl. Environ. Microbiol. 2018, 84. [CrossRef] 
50. Hein, E.M.; Rose, K.; van't Slot, G.; Friedrich, A.W.; Humpf, H.U. Deconjugation and degradation of flavonol glycosides by pig cecal microbiota characterized by Fluorescence in situ hybridization (FISH). J. Agric. Food Chem. 2008, 56, 2281-2290. [CrossRef]

51. Labib, S.; Hummel, S.; Richling, E.; Humpf, H.U.; Schreier, P. Use of the pig caecum model to mimic the human intestinal metabolism of hispidulin and related compounds. Mol. Nutr. Food Res. 2006, 50, 78-86. [CrossRef] [PubMed]

52. Tripoli, E.; Giammanco, M.; Tabacchi, G.; Di Majo, D.; Giammanco, S.; La Guardia, M. The phenolic compounds of olive oil: Structure, biological activity and beneficial effects on human health. Nutr. Res. Rev. 2005, 18, 98-112. [CrossRef] [PubMed]

53. Guo, L.; Sun, Q.; Gong, S.; Bi, X.; Jiang, W.; Xue, W.; Fei, P. Antimicrobial Activity and Action Approach of the Olive Oil Polyphenol Extract Against Listeria monocytogenes. Front. Microbiol. 2019, 10, 1586. [CrossRef] [PubMed]

54. Medina, E.; de Castro, A.; Romero, C.; Brenes, M. Comparison of the concentrations of phenolic compounds in olive oils and other plant oils: Correlation with antimicrobial activity. J. Agric. Food Chem. 2006, 54, 4954-4961. [CrossRef] [PubMed]

55. Cueva, C.; Moreno-Arribas, M.V.; Martin-Alvarez, P.J.; Bills, G.; Vicente, M.F.; Basilio, A.; Rivas, C.L.; Requena, T.; Rodriguez, J.M.; Bartolome, B. Antimicrobial activity of phenolic acids against commensal, probiotic and pathogenic bacteria. Res. Microbiol. 2010, 161, 372-382. [CrossRef] [PubMed]

56. Lee, H.C.; Jenner, A.M.; Low, C.S.; Lee, Y.K. Effect of tea phenolics and their aromatic fecal bacterial metabolites on intestinal microbiota. Res. Microbiol. 2006, 157, 876-884. [CrossRef]

57. Karaosmanoglu, H.; Soyer, F.; Ozen, B.; Tokatli, F. Antimicrobial and antioxidant activities of Turkish extra virgin olive oils. J. Agric. Food Chem. 2010, 58, 8238-8245. [CrossRef]

58. Wang, M.; Firrman, J.; Zhang, L.; Arango-Argoty, G.; Tomasula, P.; Liu, L.; Xiao, W.; Yam, K. Apigenin Impacts the Growth of the Gut Microbiota and Alters the Gene Expression of Enterococcus. Molecules 2017, 22, 1292. [CrossRef]

59. Vollmer, M.; Esders, S.; Farquharson, F.M.; Neugart, S.; Duncan, S.H.; Schreiner, M.; Louis, P.; Maul, R.; Rohn, S. Mutual Interaction of Phenolic Compounds and Microbiota: Metabolism of Complex Phenolic Apigenin-C- and Kaempferol-O-Derivatives by Human Fecal Samples. J. Agric. Food Chem. 2018, 66, 485-497. [CrossRef]

60. Radulovic, K.; Normand, S.; Rehman, A.; Delanoye-Crespin, A.; Chatagnon, J.; Delacre, M.; Waldschmitt, N.; Poulin, L.F.; Iovanna, J.; Ryffel, B.; et al. A dietary flavone confers communicable protection against colitis through NLRP6 signaling independently of inflammasome activation. Mucosal Immunol. 2018, 11, 811-819. [CrossRef]

61. Schoeler, M.; Caesar, R. Dietary lipids, gut microbiota and lipid metabolism. Rev. Endocr. Metab. Disord. 2019, 20, 461-472. [CrossRef]

62. Martin-Pelaez, S.; Mosele, J.I.; Pizarro, N.; Farras, M.; de la Torre, R.; Subirana, I.; Perez-Cano, F.J.; Castaner, O.; Sola, R.; Fernandez-Castillejo, S.; et al. Effect of virgin olive oil and thyme phenolic compounds on blood lipid profile: Implications of human gut microbiota. Eur. J. Nutr. 2017, 56, 119-131. [CrossRef]

63. Martinez, N.; Prieto, I.; Hidalgo, M.; Segarra, A.B.; Martinez-Rodriguez, A.M.; Cobo, A.; Ramirez, M.; Galvez, A.; Martinez-Canamero, M. Refined versus Extra Virgin Olive Oil High-Fat Diet Impact on Intestinal Microbiota of Mice and Its Relation to Different Physiological Variables. Microorganisms 2019, 7, 61. [CrossRef] [PubMed]

64. Hidalgo, M.; Prieto, I.; Abriouel, H.; Villarejo, A.B.; Ramirez-Sanchez, M.; Cobo, A.; Benomar, N.; Galvez, A.; Martinez-Canamero, M. Changes in Gut Microbiota Linked to a Reduction in Systolic Blood Pressure in Spontaneously Hypertensive Rats Fed an Extra Virgin Olive Oil-Enriched Diet. Plant Foods Hum. Nutr. 2018, 73, 1-6. [CrossRef]

65. Liu, Z.; Wang, N.; Ma, Y.; Wen, D. Hydroxytyrosol Improves Obesity and Insulin Resistance by Modulating Gut Microbiota in High-Fat Diet-Induced Obese Mice. Front. Microbiol. 2019, 10, 390. [CrossRef] [PubMed]

66. Zhang, Z.; Wu, X.; Cao, S.; Wang, L.; Wang, D.; Yang, H.; Feng, Y.; Wang, S.; Li, L. Caffeic acid ameliorates colitis in association with increased Akkermansia population in the gut microbiota of mice. Oncotarget 2016, 7, 31790-31799. [CrossRef] [PubMed] 
67. Ma, Y.; Chen, K.; Lv, L.; Wu, S.; Guo, Z. Ferulic acid ameliorates nonalcoholic fatty liver disease and modulates the gut microbiota composition in high-fat diet fed ApoE $\left(^{-/}\right)$mice. Biomed. Pharmacother. Biomed. Pharmacother. 2019, 113, 108753. [CrossRef] [PubMed]

68. Wang, N.; Ma, Y.; Liu, Z.; Liu, L.; Yang, K.; Wei, Y.; Liu, Y.; Chen, X.; Sun, X.; Wen, D. Hydroxytyrosol prevents PM2.5-induced adiposity and insulin resistance by restraining oxidative stress related NF-kappaB pathway and modulation of gut microbiota in a murine model. Free Radic. Biol. Med. 2019, 141, 393-407. [CrossRef]

69. Woting, A.; Blaut, M. The Intestinal Microbiota in Metabolic Disease. Nutrients 2016, 8, 202. [CrossRef]

70. Castelli, W.P.; Doyle, J.T.; Gordon, T.; Hames, C.G.; Hjortland, M.C.; Hulley, S.B.; Kagan, A.; Zukel, W.J. HDL cholesterol and other lipids in coronary heart disease. The cooperative lipoprotein phenotyping study. Circulation 1977, 55, 767-772. [CrossRef]

71. Castelli, W.P.; Garrison, R.J.; Wilson, P.W.; Abbott, R.D.; Kalousdian, S.; Kannel, W.B. Incidence of coronary heart disease and lipoprotein cholesterol levels. The Framingham Study. JAMA 1986, 256, 2835-2838. [CrossRef] [PubMed]

72. Karlsson, F.H.; Tremaroli, V.; Nookaew, I.; Bergstrom, G.; Behre, C.J.; Fagerberg, B.; Nielsen, J.; Backhed, F. Gut metagenome in European women with normal, impaired and diabetic glucose control. Nature 2013, 498, 99-103. [CrossRef] [PubMed]

73. Fu, J.; Bonder, M.J.; Cenit, M.C.; Tigchelaar, E.F.; Maatman, A.; Dekens, J.A.; Brandsma, E.; Marczynska, J.; Imhann, F.; Weersma, R.K.; et al. The Gut Microbiome Contributes to a Substantial Proportion of the Variation in Blood Lipids. Circ. Res. 2015, 117, 817-824. [CrossRef]

74. Nirmalkar, K.; Murugesan, S.; Pizano-Zarate, M.L.; Villalobos-Flores, L.E.; Garcia-Gonzalez, C.; Morales-Hernandez, R.M.; Nunez-Hernandez, J.A.; Hernandez-Quiroz, F.; Romero-Figueroa, M.D.S.; Hernandez-Guerrero, C.; et al. Gut Microbiota and Endothelial Dysfunction Markers in Obese Mexican Children and Adolescents. Nutrients 2018, 10, 9. [CrossRef] [PubMed]

75. Valdes, L.; Cuervo, A.; Salazar, N.; Ruas-Madiedo, P.; Gueimonde, M.; Gonzalez, S. The relationship between phenolic compounds from diet and microbiota: Impact on human health. Food Funct. 2015, 6, 2424-2439. [CrossRef]

76. Ehara, S.; Ueda, M.; Naruko, T.; Haze, K.; Itoh, A.; Otsuka, M.; Komatsu, R.; Matsuo, T.; Itabe, H.; Takano, T.; et al. Elevated levels of oxidized low density lipoprotein show a positive relationship with the severity of acute coronary syndromes. Circulation 2001, 103, 1955-1960. [CrossRef]

77. Toshima, S.; Hasegawa, A.; Kurabayashi, M.; Itabe, H.; Takano, T.; Sugano, J.; Shimamura, K.; Kimura, J.; Michishita, I.; Suzuki, T.; et al. Circulating oxidized low density lipoprotein levels. A biochemical risk marker for coronary heart disease. Arterioscler. Thromb. Vasc. Biol. 2000, 20, 2243-2247. [CrossRef]

78. Konstantinidou, V.; Khymenets, O.; Covas, M.I.; de la Torre, R.; Munoz-Aguayo, D.; Anglada, R.; Farre, M.; Fito, M. Time course of changes in the expression of insulin sensitivity-related genes after an acute load of virgin olive oil. OMICS A J. Integr. Biol. 2009, 13, 431-438. [CrossRef]

79. Boto-Ordonez, M.; Urpi-Sarda, M.; Queipo-Ortuno, M.I.; Tulipani, S.; Tinahones, F.J.; Andres-Lacueva, C. High levels of Bifidobacteria are associated with increased levels of anthocyanin microbial metabolites: A randomized clinical trial. Food Funct. 2014, 5, 1932-1938. [CrossRef]

80. Guglielmetti, S.; Fracassetti, D.; Taverniti, V.; Del Bo, C.; Vendrame, S.; Klimis-Zacas, D.; Arioli, S.; Riso, P.; Porrini, M. Differential modulation of human intestinal bifidobacterium populations after consumption of a wild blueberry (Vaccinium angustifolium) drink. J. Agric. Food Chem. 2013, 61, 8134-8140. [CrossRef]

81. Neyrinck, A.M.; Van Hee, V.F.; Bindels, L.B.; De Backer, F.; Cani, P.D.; Delzenne, N.M. Polyphenol-rich extract of pomegranate peel alleviates tissue inflammation and hypercholesterolaemia in high-fat diet-induced obese mice: Potential implication of the gut microbiota. Br. J. Nutr. 2013, 109, 802-809. [CrossRef] [PubMed]

82. Gibson, G.R.; Roberfroid, M.B. Dietary modulation of the human colonic microbiota: Introducing the concept of prebiotics. J. Nutr. 1995, 125, 1401-1412. [CrossRef] [PubMed]

83. Andrade, S.; Borges, N. Effect of fermented milk containing Lactobacillus acidophilus and Bifidobacterium longum on plasma lipids of women with normal or moderately elevated cholesterol. J. Dairy Res. 2009, 76, 469-474. [CrossRef] [PubMed]

84. Ejtahed, H.S.; Mohtadi-Nia, J.; Homayouni-Rad, A.; Niafar, M.; Asghari-Jafarabadi, M.; Mofid, V.; Akbarian-Moghari, A. Effect of probiotic yogurt containing Lactobacillus acidophilus and Bifidobacterium lactis on lipid profile in individuals with type 2 diabetes mellitus. J. Dairy Sci. 2011, 94, 3288-3294. [CrossRef] [PubMed] 
85. Marcelino, G.; Hiane, P.A.; Freitas, K.C.; Santana, L.F.; Pott, A.; Donadon, J.R.; Guimaraes, R.C.A. Effects of Olive Oil and Its Minor Components on Cardiovascular Diseases, Inflammation, and Gut Microbiota. Nutrients 2019, 11, 1826. [CrossRef]

86. Wu, Y.; Zhang, Q.; Ren, Y.; Ruan, Z. Effect of probiotic Lactobacillus on lipid profile: A systematic review and meta-analysis of randomized, controlled trials. PLOS ONE 2017, 12, e0178868. [CrossRef]

87. Prieto, I.; Hidalgo, M.; Segarra, A.B.; Martinez-Rodriguez, A.M.; Cobo, A.; Ramirez, M.; Abriouel, H.; Galvez, A.; Martinez-Canamero, M. Influence of a diet enriched with virgin olive oil or butter on mouse gut microbiota and its correlation to physiological and biochemical parameters related to metabolic syndrome. PLoS ONE 2018, 13, e0190368. [CrossRef]

88. Conterno, L.; Martinelli, F.; Tamburini, M.; Fava, F.; Mancini, A.; Sordo, M.; Pindo, M.; Martens, S.; Masuero, D.; Vrhovsek, U.; et al. Measuring the impact of olive pomace enriched biscuits on the gut microbiota and its metabolic activity in mildly hypercholesterolaemic subjects. Eur. J. Nutr. 2019, 58, 63-81. [CrossRef]

89. Jarocki, P.; Targonski, Z. Genetic diversity of bile salt hydrolases among human intestinal bifidobacteria. Curr. Microbiol. 2013, 67, 286-292. [CrossRef]

90. Martoni, C.J.; Labbe, A.; Ganopolsky, J.G.; Prakash, S.; Jones, M.L. Changes in bile acids, FGF-19 and sterol absorption in response to bile salt hydrolase active L. reuteri NCIMB 30242. Gut Microbes 2015, 6, 57-65. [CrossRef] [PubMed]

91. Velasco, P.F.; Ferrerira, A.; Crovesy, L.; Marine, T.; Carmo, M.G.T. Fatty Acids, Gut Microbiota, and the Genesis of Obesity. In Biochemistry and Health Benefits of Fatty Acids; IntechOpen: London, UK, 2018.

92. Wang, Z.; Klipfell, E.; Bennett, B.J.; Koeth, R.; Levison, B.S.; Dugar, B.; Feldstein, A.E.; Britt, E.B.; Fu, X.; Chung, Y.M.; et al. Gut flora metabolism of phosphatidylcholine promotes cardiovascular disease. Nature 2011, 472, 57-63. [CrossRef] [PubMed]

93. Lever, M.; George, P.M.; Slow, S.; Bellamy, D.; Young, J.M.; Ho, M.; McEntyre, C.J.; Elmslie, J.L.; Atkinson, W.; Molyneux, S.L.; et al. Betaine and Trimethylamine-N-Oxide as Predictors of Cardiovascular Outcomes Show Different Patterns in Diabetes Mellitus: An Observational Study. PLoS ONE 2014, 9, e114969. [CrossRef] [PubMed]

94. Tang, W.H.; Wang, Z.; Fan, Y.; Levison, B.; Hazen, J.E.; Donahue, L.M.; Wu, Y.; Hazen, S.L. Prognostic value of elevated levels of intestinal microbe-generated metabolite trimethylamine-N-oxide in patients with heart failure: Refining the gut hypothesis. J. Am. Coll. Cardiol. 2014, 64, 1908-1914. [CrossRef] [PubMed]

95. Wang, Z.; Roberts, A.B.; Buffa, J.A.; Levison, B.S.; Zhu, W.; Org, E.; Gu, X.; Huang, Y.; Zamanian-Daryoush, M.; Culley, M.K.; et al. Non-lethal Inhibition of Gut Microbial Trimethylamine Production for the Treatment of Atherosclerosis. Cell 2015, 163, 1585-1595. [CrossRef]

96. Wang, D.; Xia, M.; Yan, X.; Li, D.; Wang, L.; Xu, Y.; Jin, T.; Ling, W. Gut microbiota metabolism of anthocyanin promotes reverse cholesterol transport in mice via repressing miRNA-10b. Circ. Res. 2012, 111,967-981. [CrossRef]

97. Lee, M.J.; Chou, F.P.; Tseng, T.H.; Hsieh, M.H.; Lin, M.C.; Wang, C.J. Hibiscus protocatechuic acid or esculetin can inhibit oxidative LDL induced by either copper ion or nitric oxide donor. J. Agric. Food Chem. 2002, 50, 2130-2136. [CrossRef]

98. Hartley, A.; Haskard, D.; Khamis, R. Oxidized LDL and anti-oxidized LDL antibodies in atherosclerosis-Novel insights and future directions in diagnosis and therapy. Trends Cardiovasc. Med. 2019, 29, 22-26. [CrossRef]

99. Calderon-Perez, L.; Gosalbes, M.J.; Yuste, S.; Valls, R.M.; Pedret, A.; Llaurado, E.; Jimenez-Hernandez, N.; Artacho, A.; Pla-Paga, L.; Companys, J.; et al. Gut metagenomic and short chain fatty acids signature in hypertension: A cross-sectional study. Sci. Rep. 2020, 10, 6436. [CrossRef]

100. Zdunczyk, Z.; Juskiewicz, J.; Estrella, I. Cecal parameters of rats fed diets containing grapefruit polyphenols and inulin as single supplements or in a combination. Nutrition 2006, 22, 898-904. [CrossRef]

101. Kemperman, R.A.G.G.; Mondot, S.; Possemiers, S.; Marzorati, M.; Van De Wiele, T.; Dore, J.; Vaughan, E.E. Impact of polyphenols from black tea and red wine/grape juice on a gut model microbiome. Food Res. Int. 2013, 53, 659-669. [CrossRef]

102. Macfarlane, S.; Macfarlane, G.T. Regulation of short-chain fatty acid production. Proc. Nutr. Soc. 2003, 62, 67-72. [CrossRef] [PubMed]

103. Arora, T.; Sharma, R.; Frost, G. Propionate. Anti-obesity and satiety enhancing factor? Appetite 2011, 56, 511-515. [CrossRef] 
104. Alvarez-Laderas, I.; Ramos, T.L.; Medrano, M.; Caracuel-Garcia, R.; Barbado, M.V.; Sanchez-Hidalgo, M.; Zamora, R.; Alarcon-de-la-Lastra, C.; Hidalgo, F.J.; Piruat, J.I.; et al. Polyphenolic Extract (PE) from Olive Oil Exerts a Potent Immunomodulatory Effect and Prevents Graft-versus-Host Disease in a Mouse Model. Biol. Blood Marrow Transplant. J. Am. Soc. Blood Marrow Transplant. 2020, 26, 615-624. [CrossRef] [PubMed]

105. Kau, A.L.; Ahern, P.P.; Griffin, N.W.; Goodman, A.L.; Gordon, J.I. Human nutrition, the gut microbiome and the immune system. Nature 2011, 474, 327-336. [CrossRef] [PubMed]

106. Forbes, J.D.; Van Domselaar, G.; Bernstein, C.N. The Gut Microbiota in Immune-Mediated Inflammatory Diseases. Front. Microbiol. 2016, 7, 1081. [CrossRef]

107. Belkaid, Y.; Hand, T.W. Role of the microbiota in immunity and inflammation. Cell 2014, 157, $121-141$. [CrossRef]

108. Shamriz, O.; Mizrahi, H.; Werbner, M.; Shoenfeld, Y.; Avni, O.; Koren, O. Microbiota at the crossroads of autoimmunity. Autoimmun. Rev. 2016, 15, 859-869. [CrossRef]

109. Hevia, A.; Milani, C.; Lopez, P.; Cuervo, A.; Arboleya, S.; Duranti, S.; Turroni, F.; Gonzalez, S.; Suarez, A.; Gueimonde, M.; et al. Intestinal dysbiosis associated with systemic lupus erythematosus. mBio 2014, 5, e01548-14. [CrossRef]

110. Rogier, R.; Evans-Marin, H.; Manasson, J.; van der Kraan, P.M.; Walgreen, B.; Helsen, M.M.; van den Bersselaar, L.A.; van de Loo, F.A.; van Lent, P.L.; Abramson, S.B.; et al. Alteration of the intestinal microbiome characterizes preclinical inflammatory arthritis in mice and its modulation attenuates established arthritis. Sci. Rep. 2017, 7, 15613. [CrossRef]

111. Siddiqui, H.; Chen, T.; Aliko, A.; Mydel, P.M.; Jonsson, R.; Olsen, I. Microbiological and bioinformatics analysis of primary Sjogren's syndrome patients with normal salivation. J. Oral Microbiol. 2016, 8, 31119. [CrossRef]

112. Martin-Pelaez, S.; Castaner, O.; Sola, R.; Motilva, M.J.; Castell, M.; Perez-Cano, F.J.; Fito, M. Influence of Phenol-Enriched Olive Oils on Human Intestinal Immune Function. Nutrients 2016, 8, 213. [CrossRef] [PubMed]

113. Lazar, V.; Ditu, L.M.; Pircalabioru, G.G.; Picu, A.; Petcu, L.; Cucu, N.; Chifiriuc, M.C. Gut Microbiota, Host Organism, and Diet Trialogue in Diabetes and Obesity. Front. Nutr. 2019, 6, 21. [CrossRef] [PubMed]

114. Covas, M.I.; de la Torre, R.; Fito, M. Virgin olive oil: A key food for cardiovascular risk protection. Br. J. Nutr. 2015, 113 (Suppl. 2), S19-S28. [CrossRef]

115. Hashmi, M.A.; Khan, A.; Hanif, M.; Farooq, U.; Perveen, S. Traditional Uses, Phytochemistry, and Pharmacology of Olea europaea (Olive). Evid. Based Complementary Altern. Med. 2015, 2015, 541591. [CrossRef]

116. Rigacci, S.; Stefani, M. Nutraceutical Properties of Olive Oil Polyphenols. An Itinerary from Cultured Cells through Animal Models to Humans. Int. J. Mol. Sci. 2016, 17, 843. [CrossRef]

117. Tomasello, G.; Mazzola, M.; Leone, A.; Sinagra, E.; Zummo, G.; Farina, F.; Damiani, P.; Cappello, F.; Gerges Geagea, A.; Jurjus, A.; et al. Nutrition, oxidative stress and intestinal dysbiosis: Influence of diet on gut microbiota in inflammatory bowel diseases. Biomed. Pap. Med. Fac. Univ. Palacky Olomouc Czechoslov. 2016, 160, 461-466. [CrossRef]

118. Santangelo, C.; Vari, R.; Scazzocchio, B.; De Sanctis, P.; Giovannini, C.; D’Archivio, M.; Masella, R. Anti-inflammatory Activity of Extra Virgin Olive Oil Polyphenols: Which Role in the Prevention and Treatment of Immune-Mediated Inflammatory Diseases? Endocr. Metab. Immune Disord. Drug Targets 2018, 18, 36-50. [CrossRef]

119. Fito, M.; Cladellas, M.; de la Torre, R.; Marti, J.; Munoz, D.; Schroder, H.; Alcantara, M.; Pujadas-Bastardes, M.; Marrugat, J.; Lopez-Sabater, M.C.; et al. Anti-inflammatory effect of virgin olive oil in stable coronary disease patients: A randomized, crossover, controlled trial. Eur. J. Clin. Nutr. 2008, 62, 570-574. [CrossRef]

120. Santangelo, C.; Filesi, C.; Vari, R.; Scazzocchio, B.; Filardi, T.; Fogliano, V.; D’Archivio, M.; Giovannini, C.; Lenzi, A.; Morano, S.; et al. Consumption of extra-virgin olive oil rich in phenolic compounds improves metabolic control in patients with type 2 diabetes mellitus: A possible involvement of reduced levels of circulating visfatin. J. Endocrinol. Investig. 2016, 39, 1295-1301. [CrossRef]

121. Lama, A.; Pirozzi, C.; Mollica, M.P.; Trinchese, G.; Di Guida, F.; Cavaliere, G.; Calignano, A.; MattaceRaso, G.; BerniCanani, R.; Meli, R. Polyphenol-rich virgin olive oil reduces insulin resistance and liver inflammation and improves mitochondrial dysfunction in high-fat diet fed rats. Mol. Nutr. Food Res. 2017, 61. [CrossRef] 
122. Jurado-Ruiz, E.; Varela, L.M.; Luque, A.; Berna, G.; Cahuana, G.; Martinez-Force, E.; Gallego-Duran, R.; Soria, B.; de Roos, B.; Romero Gomez, M.; et al. An extra virgin olive oil rich diet intervention ameliorates the nonalcoholic steatohepatitis induced by a high-fat "Western-type" diet in mice. Mol. Nutr. Food Res. 2017, 61. [CrossRef]

123. Aparicio-Soto, M.; Sanchez-Hidalgo, M.; Cardeno, A.; Rosillo, M.A.; Sanchez-Fidalgo, S.; Utrilla, J.; Martin-Lacave, I.; Alarcon-de-la-Lastra, C. Dietary extra virgin olive oil attenuates kidney injury in pristane-induced SLE model via activation of HO-1/Nrf-2 antioxidant pathway and suppression of JAK/STAT, NF-kappaB and MAPK activation. J. Nutr. Biochem. 2016, 27, 278-288. [CrossRef] [PubMed]

124. D'Amore, S.; Vacca, M.; Cariello, M.; Graziano, G.; D'Orazio, A.; Salvia, R.; Sasso, R.C.; Sabba, C.; Palasciano, G.; Moschetta, A. Genes and miRNA expression signatures in peripheral blood mononuclear cells in healthy subjects and patients with metabolic syndrome after acute intake of extra virgin olive oil. Biochim. Biophys. Acta 2016, 1861, 1671-1680. [CrossRef] [PubMed]

125. Boss, A.; Kao, C.H.; Murray, P.M.; Marlow, G.; Barnett, M.P.; Ferguson, L.R. Human Intervention Study to Assess the Effects of Supplementation with Olive Leaf Extract on Peripheral Blood Mononuclear Cell Gene Expression. Int. J. Mol. Sci. 2016, 17, 2019. [CrossRef] [PubMed]

126. Fito, M.; Cladellas, M.; de la Torre, R.; Marti, J.; Alcantara, M.; Pujadas-Bastardes, M.; Marrugat, J.; Bruguera, J.; Lopez-Sabater, M.C.; Vila, J.; et al. Antioxidant effect of virgin olive oil in patients with stable coronary heart disease: A randomized, crossover, controlled, clinical trial. Atherosclerosis 2005, 181, 149-158. [CrossRef] [PubMed]

127. Rosillo, M.A.; Sanchez-Hidalgo, M.; Sanchez-Fidalgo, S.; Aparicio-Soto, M.; Villegas, I.; Alarcon-de-laLastra, C. Dietary extra-virgin olive oil prevents inflammatory response and cartilage matrix degradation in murine collagen-induced arthritis. Eur. J. Nutr. 2016, 55, 315-325. [CrossRef]

128. Parkinson, L.; Cicerale, S. The Health Benefiting Mechanisms of Virgin Olive Oil Phenolic Compounds. Molecules 2016, 21, 1734. [CrossRef]

129. Cicerale, S.; Lucas, L.; Keast, R. Biological activities of phenolic compounds present in virgin olive oil. Int. J. Mol. Sci. 2010, 11, 458-479. [CrossRef]

130. Barbaro, B.; Toietta, G.; Maggio, R.; Arciello, M.; Tarocchi, M.; Galli, A.; Balsano, C. Effects of the olive-derived polyphenol oleuropein on human health. Int. J. Mol. Sci. 2014, 15, 18508-18524. [CrossRef]

131. Bulotta, S.; Celano, M.; Lepore, S.M.; Montalcini, T.; Pujia, A.; Russo, D. Beneficial effects of the olive oil phenolic components oleuropein and hydroxytyrosol: Focus on protection against cardiovascular and metabolic diseases. J. Transl. Med. 2014, 12, 219. [CrossRef]

132. Lu, J.; Huang, G.; Wang, Z.; Zhuang, S.; Xu, L.; Song, B.; Xiong, Y.; Guan, S. Tyrosol exhibits negative regulatory effects on LPS response and endotoxemia. Food Chem. Toxicol. Int. J. Publ. Br. Ind. Biol. Res. Assoc. 2013, 62, 172-178. [CrossRef] [PubMed]

133. Beauchamp, G.K.; Keast, R.S.; Morel, D.; Lin, J.; Pika, J.; Han, Q.; Lee, C.H.; Smith, A.B.; Breslin, P.A. Phytochemistry: Ibuprofen-like activity in extra-virgin olive oil. Nature 2005, 437, 45-46. [CrossRef] [PubMed]

134. Martin, M.A.; Ramos, S.; Granado-Serrano, A.B.; Rodriguez-Ramiro, I.; Trujillo, M.; Bravo, L.; Goya, L. Hydroxytyrosol induces antioxidant/detoxificant enzymes and $\mathrm{Nrf} 2$ translocation via extracellular regulated kinases and phosphatidylinositol-3-kinase/protein kinase B pathways in HepG2 cells. Mol. Nutr. Food Res. 2010, 54, 956-966. [CrossRef] [PubMed]

135. Bouayed, J.; Bohn, T. Exogenous antioxidants-Double-edged swords in cellular redox state: Health beneficial effects at physiologic doses versus deleterious effects at high doses. Oxid. Med. Cell. Longev. 2010, 3, 228-237. [CrossRef] [PubMed]

136. Matijaca, H.; Gacina, P.; Rincic, G.; Matijaca, A.; Josipovic, J.; Stojsavljevic, S. Effects of Occupational Stress on the Activation of Hemostatic and Inflammatory System. Acta Clin. Croat. 2019, 58, 281-287. [CrossRef]

137. Yu, R.; Tian, L.; Ding, Y.; Gao, Y.; Li, D.; Tang, Y. Correlation between inflammatory markers and impaired circadian clock gene expression in type 2 diabetes mellitus. Diabetes Res. Clin. Pract. 2019, 156, 107831. [CrossRef]

138. Schwedhelm, C.; Schwingshackl, L.; Agogo, G.O.; Sonestedt, E.; Boeing, H.; Knuppel, S. Associations of food groups and cardiometabolic and inflammatory biomarkers: Does the meal matter? Br. J. Nutr. 2019, 122, 707-716. [CrossRef] 
139. Valls, R.M.; Farras, M.; Suarez, M.; Fernandez-Castillejo, S.; Fito, M.; Konstantinidou, V.; Fuentes, F.; Lopez-Miranda, J.; Giralt, M.; Covas, M.I.; et al. Effects of functional olive oil enriched with its own phenolic compounds on endothelial function in hypertensive patients. A randomised controlled trial. Food Chem. 2015, 167, 30-35. [CrossRef]

140. Berbert, A.A.; Kondo, C.R.; Almendra, C.L.; Matsuo, T.; Dichi, I. Supplementation of fish oil and olive oil in patients with rheumatoid arthritis. Nutrition 2005, 21, 131-136. [CrossRef]

141. Barrea, L.; Balato, N.; Di Somma, C.; Macchia, P.E.; Napolitano, M.; Savanelli, M.C.; Esposito, K.; Colao, A.; Savastano, S. Nutrition and psoriasis: Is there any association between the severity of the disease and adherence to the Mediterranean diet? J. Transl. Med. 2015, 13, 18. [CrossRef]

142. Michalsen, A.; Eddin, O.; Salama, A. A case series of the effects of a novel composition of a traditional natural preparation for the treatment of psoriasis. J. Tradit. Complementary Med. 2016, 6, 395-398. [CrossRef] [PubMed]

143. Liu, Y.; Alookaran, J.J.; Rhoads, J.M. Probiotics in Autoimmune and Inflammatory Disorders. Nutrients 2018, 10, 1537. [CrossRef] [PubMed]

144. Pozuelo, M.; Panda, S.; Santiago, A.; Mendez, S.; Accarino, A.; Santos, J.; Guarner, F.; Azpiroz, F.; Manichanh, C. Reduction of butyrate- and methane-producing microorganisms in patients with Irritable Bowel Syndrome. Sci. Rep. 2015, 5, 12693. [CrossRef]

145. Borody, T.J.; Warren, E.F.; Leis, S.M.; Surace, R.; Ashman, O.; Siarakas, S. Bacteriotherapy using fecal flora: Toying with human motions. J. Clin. Gastroenterol. 2004, 38, 475-483. [CrossRef] [PubMed]

146. Ford, A.C.; Spiegel, B.M.; Talley, N.J.; Moayyedi, P. Small intestinal bacterial overgrowth in irritable bowel syndrome: Systematic review and meta-analysis. Clin. Gastroenterol. Hepatol. Off. Clin. Pract. J. Am. Gastroenterol. Assoc. 2009, 7, 1279-1286. [CrossRef]

147. Hoveyda, N.; Heneghan, C.; Mahtani, K.R.; Perera, R.; Roberts, N.; Glasziou, P. A systematic review and meta-analysis: Probiotics in the treatment of irritable bowel syndrome. BMC Gastroenterol. 2009, 9, 15. [CrossRef]

148. Tian, H.; Ding, C.; Gong, J.; Ge, X.; McFarland, L.V.; Gu, L.; Wei, Y.; Chen, Q.; Zhu, W.; Li, J.; et al. Treatment of Slow Transit Constipation With Fecal Microbiota Transplantation: A Pilot Study. J. Clin. Gastroenterol. 2016, 50, 865-870. [CrossRef]

149. Chavez-Carbajal, A.; Nirmalkar, K.; Perez-Lizaur, A.; Hernandez-Quiroz, F.; Ramirez-Del-Alto, S.; Garcia-Mena, J.; Hernandez-Guerrero, C. Gut Microbiota and Predicted Metabolic Pathways in a Sample of Mexican Women Affected by Obesity and Obesity Plus Metabolic Syndrome. Int. J. Mol. Sci. 2019, 20, 438. [CrossRef]

150. Baothman, O.A.; Zamzami, M.A.; Taher, I.; Abubaker, J.; Abu-Farha, M. The role of Gut Microbiota in the development of obesity and Diabetes. Lipids Health Dis. 2016, 15, 108. [CrossRef]

151. Van Hul, M.; Cani, P.D. Targeting Carbohydrates and Polyphenols for a Healthy Microbiome and Healthy Weight. Curr. Nutr. Rep. 2019, 8, 307-316. [CrossRef]

152. Meydani, M.; Hasan, S.T. Dietary polyphenols and obesity. Nutrients 2010, 2, 737-751. [CrossRef] [PubMed]

153. Galvao Candido, F.; Xavier Valente, F.; da Silva, L.E.; Goncalves Leao Coelho, O.; Gouveia Peluzio, M.D.C.; Goncalves Alfenas, R.C. Consumption of extra virgin olive oil improves body composition and blood pressure in women with excess body fat: A randomized, double-blinded, placebo-controlled clinical trial. Eur. J. Nutr. 2018, 57, 2445-2455. [CrossRef]

154. Drira, R.; Chen, S.; Sakamoto, K. Oleuropein and hydroxytyrosol inhibit adipocyte differentiation in 3 T3-L1 cells. Life Sci. 2011, 89, 708-716. [CrossRef] [PubMed]

155. Peyrol, J.; Riva, C.; Amiot, M.J. Hydroxytyrosol in the Prevention of the Metabolic Syndrome and Related Disorders. Nutrients 2017, 9, 306. [CrossRef] [PubMed]

156. Scoditti, E.; Carpi, S.; Massaro, M.; Pellegrino, M.; Polini, B.; Carluccio, M.A.; Wabitsch, M.; Verri, T.; Nieri, P.; De Caterina, R. Hydroxytyrosol Modulates Adipocyte Gene and miRNA Expression Under Inflammatory Condition. Nutrients 2019, 11, 2493. [CrossRef]

157. Wang, N.; Liu, Y.; Ma, Y.; Wen, D. Hydroxytyrosol ameliorates insulin resistance by modulating endoplasmic reticulum stress and prevents hepatic steatosis in diet-induced obesity mice. J. Nutr. Biochem. 2018, 57, 180-188. [CrossRef]

158. Castro-Barquero, S.; Lamuela-Raventos, R.M.; Domenech, M.; Estruch, R. Relationship between Mediterranean Dietary Polyphenol Intake and Obesity. Nutrients 2018, 10, 1523. [CrossRef] 
159. Backhed, F.; Ding, H.; Wang, T.; Hooper, L.V.; Koh, G.Y.; Nagy, A.; Semenkovich, C.F.; Gordon, J.I. The gut microbiota as an environmental factor that regulates fat storage. Proc. Natl. Acad. Sci. USA 2004, 101, 15718-15723. [CrossRef]

160. Gomes, A.C.; Hoffmann, C.; Mota, J.F. The human gut microbiota: Metabolism and perspective in obesity. Gut Microbes 2018, 9, 308-325. [CrossRef]

161. Healey, G.R.; Murphy, R.; Brough, L.; Butts, C.A.; Coad, J. Interindividual variability in gut microbiota and host response to dietary interventions. Nutr. Rev. 2017, 75, 1059-1080. [CrossRef]

162. Turnbaugh, P.J.; Hamady, M.; Yatsunenko, T.; Cantarel, B.L.; Duncan, A.; Ley, R.E.; Sogin, M.L.; Jones, W.J.; Roe, B.A.; Affourtit, J.P.; et al. A core gut microbiome in obese and lean twins. Nature 2009, 457, 480-484. [CrossRef] [PubMed]

163. Ley, R.E.; Turnbaugh, P.J.; Klein, S.; Gordon, J.I. Microbial ecology: Human gut microbes associated with obesity. Nature 2006, 444, 1022-1023. [CrossRef] [PubMed]

164. Schwiertz, A.; Taras, D.; Schafer, K.; Beijer, S.; Bos, N.A.; Donus, C.; Hardt, P.D. Microbiota and SCFA in lean and overweight healthy subjects. Obesity 2010, 18, 190-195. [CrossRef] [PubMed]

165. Murphy, E.F.; Cotter, P.D.; Healy, S.; Marques, T.M.; O’Sullivan, O.; Fouhy, F.; Clarke, S.F.; O’Toole, P.W.; Quigley, E.M.; Stanton, C.; et al. Composition and energy harvesting capacity of the gut microbiota: Relationship to diet, obesity and time in mouse models. Gut 2010, 59, 1635-1642. [CrossRef]

166. Turnbaugh, P.J.; Backhed, F.; Fulton, L.; Gordon, J.I. Diet-induced obesity is linked to marked but reversible alterations in the mouse distal gut microbiome. Cell Host Microbe 2008, 3, 213-223. [CrossRef]

167. Peters, B.A.; Shapiro, J.A.; Church, T.R.; Miller, G.; Trinh-Shevrin, C.; Yuen, E.; Friedlander, C.; Hayes, R.B.; Ahn, J. A taxonomic signature of obesity in a large study of American adults. Sci. Rep. 2018, 8, 9749. [CrossRef]

168. Kasai, C.; Sugimoto, K.; Moritani, I.; Tanaka, J.; Oya, Y.; Inoue, H.; Tameda, M.; Shiraki, K.; Ito, M.; Takei, Y.; et al. Comparison of the gut microbiota composition between obese and non-obese individuals in a Japanese population, as analyzed by terminal restriction fragment length polymorphism and next-generation sequencing. BMC Gastroenterol. 2015, 15, 100. [CrossRef]

169. Eid, H.M.; Wright, M.L.; Anil Kumar, N.V.; Qawasmeh, A.; Hassan, S.T.S.; Mocan, A.; Nabavi, S.M.; Rastrelli, L.; Atanasov, A.G.; Haddad, P.S. Significance of Microbiota in Obesity and Metabolic Diseases and the Modulatory Potential by Medicinal Plant and Food Ingredients. Front. Pharmacol. 2017, 8, 387. [CrossRef]

170. Millman, J.; Okamoto, S.; Kimura, A.; Uema, T.; Higa, M.; Yonamine, M.; Namba, T.; Ogata, E.; Yamazaki, S.; Shimabukuro, M.; et al. Metabolically and immunologically beneficial impact of extra virgin olive and flaxseed oils on composition of gut microbiota in mice. Eur. J. Nutr. 2019. [CrossRef]

171. Crovesy, L.; Ostrowski, M.; Ferreira, D.; Rosado, E.L.; Soares-Mota, M. Effect of Lactobacillus on body weight and body fat in overweight subjects: A systematic review of randomized controlled clinical trials. Int. J. Obes. 2017, 41, 1607-1614. [CrossRef]

172. An, H.M.; Park, S.Y.; Lee, D.K.; Kim, J.R.; Cha, M.K.; Lee, S.W.; Lim, H.T.; Kim, K.J.; Ha, N.J. Antiobesity and lipid-lowering effects of Bifidobacterium spp. in high fat diet-induced obese rats. Lipids Health Dis. 2011, 10, 116. [CrossRef] [PubMed]

173. Bliss, E.S.; Whiteside, E. The Gut-Brain Axis, the Human Gut Microbiota and Their Integration in the Development of Obesity. Front. Physiol. 2018, 9, 900. [CrossRef] [PubMed]

174. Cani, P.D.; Everard, A.; Duparc, T. Gut microbiota, enteroendocrine functions and metabolism. Curr. Opin. Pharmacol. 2013, 13, 935-940. [CrossRef] [PubMed]

175. Lin, H.V.; Frassetto, A.; Kowalik, E.J., Jr.; Nawrocki, A.R.; Lu, M.M.; Kosinski, J.R.; Hubert, J.A.; Szeto, D.; Yao, X.; Forrest, G.; et al. Butyrate and propionate protect against diet-induced obesity and regulate gut hormones via free fatty acid receptor 3-independent mechanisms. PLoS ONE 2012, 7, e35240. [CrossRef] [PubMed]

176. Rothenberg, D.O.; Zhou, C.; Zhang, L. A Review on the Weight-Loss Effects of Oxidized Tea Polyphenols. Molecules 2018, 23, 1176. [CrossRef]

177. Rahat-Rozenbloom, S.; Fernandes, J.; Gloor, G.B.; Wolever, T.M. Evidence for greater production of colonic short-chain fatty acids in overweight than lean humans. Int. J. Obes. 2014, 38, 1525-1531. [CrossRef]

178. de la Cuesta-Zuluaga, J.; Mueller, N.T.; Alvarez-Quintero, R.; Velasquez-Mejia, E.P.; Sierra, J.A.; Corrales-Agudelo, V.; Carmona, J.A.; Abad, J.M.; Escobar, J.S. Higher Fecal Short-Chain Fatty Acid Levels Are Associated with Gut Microbiome Dysbiosis, Obesity, Hypertension and Cardiometabolic Disease Risk Factors. Nutrients 2018, 11, 51. [CrossRef] 
179. Jumpertz, R.; Le, D.S.; Turnbaugh, P.J.; Trinidad, C.; Bogardus, C.; Gordon, J.I.; Krakoff, J. Energy-balance studies reveal associations between gut microbes, caloric load, and nutrient absorption in humans. Am. J. Clin. Nutr. 2011, 94, 58-65. [CrossRef]

180. Liu, H.; Wang, J.; He, T.; Becker, S.; Zhang, G.; Li, D.; Ma, X. Butyrate: A Double-Edged Sword for Health? Adv. Nutr. 2018, 9, 21-29. [CrossRef]

181. Cani, P.D.; Possemiers, S.; Van de Wiele, T.; Guiot, Y.; Everard, A.; Rottier, O.; Geurts, L.; Naslain, D.; Neyrinck, A.; Lambert, D.M.; et al. Changes in gut microbiota control inflammation in obese mice through a mechanism involving GLP-2-driven improvement of gut permeability. Gut 2009, 58, 1091-1103. [CrossRef]

182. Sanchez-Fidalgo, S.; Villegas, I.; Aparicio-Soto, M.; Cardeno, A.; Rosillo, M.A.; Gonzalez-Benjumea, A.; Marset, A.; Lopez, O.; Maya, I.; Fernandez-Bolanos, J.G.; et al. Effects of dietary virgin olive oil polyphenols: Hydroxytyrosyl acetate and 3, 4-dihydroxyphenylglycol on DSS-induced acute colitis in mice. J. Nutr. Biochem. 2015, 26, 513-520. [CrossRef] [PubMed]

183. Lobionda, S.; Sittipo, P.; Kwon, H.Y.; Lee, Y.K. The Role of Gut Microbiota in Intestinal Inflammation with Respect to Diet and Extrinsic Stressors. Microorganisms 2019, 7, 271. [CrossRef] [PubMed]

184. Everard, A.; Belzer, C.; Geurts, L.; Ouwerkerk, J.P.; Druart, C.; Bindels, L.B.; Guiot, Y.; Derrien, M.; Muccioli, G.G.; Delzenne, N.M.; et al. Cross-talk between Akkermansiamuciniphila and intestinal epithelium controls diet-induced obesity. Proc. Natl. Acad. Sci. USA 2013, 110, 9066-9071. [CrossRef]

185. Depommier, C.; Everard, A.; Druart, C.; Plovier, H.; Van Hul, M.; Vieira-Silva, S.; Falony, G.; Raes, J.; Maiter, D.; Delzenne, N.M.; et al. Supplementation with Akkermansiamuciniphila in overweight and obese human volunteers: A proof-of-concept exploratory study. Nat. Med. 2019, 25, 1096-1103. [CrossRef] [PubMed]

186. Zhou, K. Strategies to promote abundance of Akkermansiamuciniphila, an emerging probiotics in the gut, evidence from dietary intervention studies. J. Funct. Foods 2017, 33, 194-201. [CrossRef]

187. Pierre, J.F.; Heneghan, A.F.; Feliciano, R.P.; Shanmuganayagam, D.; Roenneburg, D.A.; Krueger, C.G.; Reed, J.D.; Kudsk, K.A. Cranberry proanthocyanidins improve the gut mucous layer morphology and function in mice receiving elemental enteral nutrition. JPEN J. Parenter. Enter. Nutr. 2013, 37, 401-409. [CrossRef]

188. Anhe, F.F.; Varin, T.V.; Le Barz, M.; Desjardins, Y.; Levy, E.; Roy, D.; Marette, A. Gut Microbiota Dysbiosis in Obesity-Linked Metabolic Diseases and Prebiotic Potential of Polyphenol-Rich Extracts. Curr. Obes. Rep. 2015, 4, 389-400. [CrossRef] 